\title{
An Extraction Method for Long-Term Tropical Cyclone Precipitation from Daily Rain Gauges $\mathscr{O}$
}

\author{
LAIYIN ZHU \\ Department of Geography, Western Michigan University, Kalamazoo, Michigan \\ STEVEN M. QUIRING \\ Atmospheric Sciences Program, Department of Geography, The Ohio State University, Columbus, Ohio
}

(Manuscript received 20 December 2016, in final form 13 July 2017)

\begin{abstract}
Tropical cyclone precipitation (TCP) can cause significant flooding in coastal areas around the world. This study compares multiple options of a new technique for developing a gridded daily TCP product at a spatial resolution of $0.25^{\circ}$. These options were evaluated using NASA's Tropical Rainfall Measuring Mission (TRMM) Multisatellite Precipitation Analysis (TMPA) 3B42 product to determine the optimal approach. Results indicate that the technique is very sensitive to changes in wind corrections, interpolation method, and gauge density. The optimal method accounts for wind-induced gauge undercatch and uses a customized interpolation approach. It significantly reduces precipitation biases associated with gauge undercatch during windy conditions. The new TCP extraction approach can be used to examine variability and long-term trends in TCP, even in regions with relatively few gauges.
\end{abstract}

\section{Introduction}

Tropical cyclones (TCs) are natural hazards that have a significant impact on coastal communities around the world (Mendelsohn et al. 2012; Pielke et al. 2008; Pielke and Landsea 1998). TCs are associated with heavy precipitation because of their convective nature, and these tropical cyclone precipitation (TCP) events are often some of the most extreme events, with severe social and economic impacts to coastal communities (Knight and Davis 2009; Kunkel et al. 2010; Zhu and Quiring 2013). Severe flooding can result from TCP events (Cerveny and Newman 2000; Villarini et al. 2011; Zhu et al. 2015). Compared to research on TC wind and storm surge, there are relatively few studies focused on historical variations in TCP and potential future changes (Hernández Ayala and Matyas 2016; Konrad and Perry 2010; Matyas 2015; Villarini et al. 2014). Many studies indicate that anthropogenic climate change will induce

\footnotetext{
Supplemental information related to this paper is available at the Journals Online website: https://doi.org/10.1175/JHM-D-160291.s1.
}

Corresponding author: Laiyin Zhu, laiyin.zhu@wmich.edu more intense TCs in the future mainly due to increasing sea surface temperatures (SSTs; Emanuel 2013; Knutson et al. 2010; Walsh et al. 2015). However, there is debate about historical and future trends in regional and global TC activity due to uncertainties in both historical observations and modeling techniques (Knutson et al. 2010; Landsea et al. 2006; Mann et al. 2009; Walsh et al. 2015).

There have been many large-scale observational studies of TCP that were based on satellite data (Benedetti et al. 2005; Jiang and Ramirez 2013; Jiang et al. 2008; Lonfat et al. 2004; Prat and Nelson 2013; Shepherd et al. 2007; Zick and Matyas 2016). Satellite data are useful when monitoring TCs over the ocean and in regions with few observation networks. Tropical Rainfall Measuring Mission (TRMM) Multisatellite Precipitation Analysis (TMPA) 3B42 (TRMM hereafter) has a near-global $\left(50^{\circ} \mathrm{S}-50^{\circ} \mathrm{N}\right)$ coverage of subdaily precipitation observations with a spatial resolution of $0.25^{\circ}$. Remotely sensed precipitation products usually have a relatively short period of record. For example, TRMM only has coverage between 1998 and 2015. This makes it challenging to assess long-term trends (Ashouri et al. 2015). It is even more challenging for both dynamical and statistical downscaling models to accurately simulate long-term variations in TCP because of difficulties in 
simulating the cyclone genesis and intensification process as well as the uncertainties and scale mismatches in the general circulation models (Hill and Lackmann 2011; Knutson et al. 2013). Therefore, daily rain gauge measurements are well suited for developing a longterm record of terrestrial TCP because they provide a longer period of record (more than 50 years) and they are based on direct measurements. Several previous studies have discussed variations in TCP along the Atlantic coast on the United States based on gauge observations (Barlow 2011; Knight and Davis 2009; Kunkel et al. 2010). Zhu and Quiring (2013) developed a technique called the Moving Radius of Outermost Closed Isobar (ROCI) Boundary Technique (MRBT) to extract daily TCP information from rain gauges. MRBT considers variations in TC size and translation speed to identify which gauges have received TCP. The goal of this paper is to update and optimize the MRBT method and to verify it using TRMM. We will also test influence from gauge density to our verification accuracy.

This paper is organized as follows. Section 2 will introduce the precipitation and TC data, our updated methods for extracting TCP, and the verification process. Section 3 will show the results of the comparisons between our gauge-based TCP and TRMM, including how it varies with rain gauge density change. Sections 4 and 5 will discuss the results and conclude with major findings.

\section{Data and methods}

This study uses precipitation data from both rain gauges and TRMM. The rain gauge data are obtained from two sources. The Daily Global Historical Climatology Network (GHCN-D) (Menne et al. 2012) has good spatial coverage of the United States. However, there is little data from Mexico in the GHCN-D, especially during the early part of the twentieth century. Therefore, we obtained a second daily gauge dataset with help from the National Weather Service of Mexico (Servicio Meteorológico Nacional of the National Water Commission). The Mexico dataset extends the rain gauge observations of the whole North American continent back to 1930s. The TRMM 3B42 (V7) is used for comparison and verification because it is a very reliable precipitation product that has been used in many previous TCP studies (Jiang and Ramirez 2013; Jiang and Zipser 2010; Jiang et al. 2011; Prat and Nelson 2013; Wang and Wolff 2012; Zhao and Yatagai 2014). The TRMM V7 has lower bias and improved representation of precipitation than its previous versions because the new algorithm considers the reflectivity-precipitation relationship, terrains, and bias corrections (Zulkafli et al. 2014). Several studies have discussed the uncertainties associated with the TRMM product, especially the issue of overestimation of low-rate precipitation and underestimation of high-rate precipitation, especially in tropical cyclones (AghaKouchak et al. 2011; Chen et al. 2013a). In this study, we choose the TRMM product as the main source of verification data because it has a 3-h temporal resolution with a $0.25^{\circ}$ spatial resolution (identical as our final TCP product) and the data are available from 1998 to 2015 with coverage between $50^{\circ} \mathrm{N}$ and $50^{\circ} \mathrm{S}$ (including Mexico). We will address the possible uncertainties in TRMM in the discussion session.

The research design of this study is shown in Fig. 1. We use gauge data to develop a new version of the TCP extraction method and then use the TRMM product for verification. We will still define our new method as MRBT, but now it stands for Moving Radius Boundary Technique since we will test two definitions of TC radius rather than one ROCI option. We tested multiple options of input parameters of the MRBT for extracting TCP. Each of these options was compared against the TRMM by using the complete 1998-2012 rain gauge data as well as the same rain gauge data sampled by the historical low gauge density. We choose 1998-2012 because it is the time when TRMM data are available. We tested the low gauge density case since a consistent gauge density will guarantee our future study on longterm trends and variations of TCP will not be biased by variations in gauge density. Figure 2 shows the spatial distribution of rain gauge density for five time periods (1891-1920, 1921-50, 1951-80, 1981-97, 1998-2012) and the lowest density in any period between 1920 and 2012 (Fig. 2f), summarized in $1^{\circ}$ grid cells. The most recent time period (1998-2012) has the highest density of rain gauges. Although the density of rain gauges in the GHCN dataset has changed significantly over time in the mainland United States, most regions have had a density of $\sim 20$ gauges per $1^{\circ}$. We will use the lowest density in Fig. $2 \mathrm{f}$ to sample the rain gauges between 1998 and 2012 (Fig. 2e) in this study to construct our verification analysis for the low gauge density case.

An important improvement to the MRBT approach developed by Zhu and Quiring (2013) is a wind correction that accounts for gauge undercatch. Since a rain gauge causes turbulence that distorts the wind field and displaces rain drops, a portion of the rainfall is not collected by the gauge. Many studies have discussed this issue, especially for solid precipitation, and developed parametric or dynamic models for bias adjustment (Habib et al.1999; Stisen et al. 2012; Yang et al. 1999). Although gauge undercatch is most pronounced for snow, gauge undercatch can also be an issue for rainfall, especially when rain is associated with strong winds. Here we used the newest version of the Holland parametric wind field model (Holland et al. 2010) to estimate the surface wind speed at 


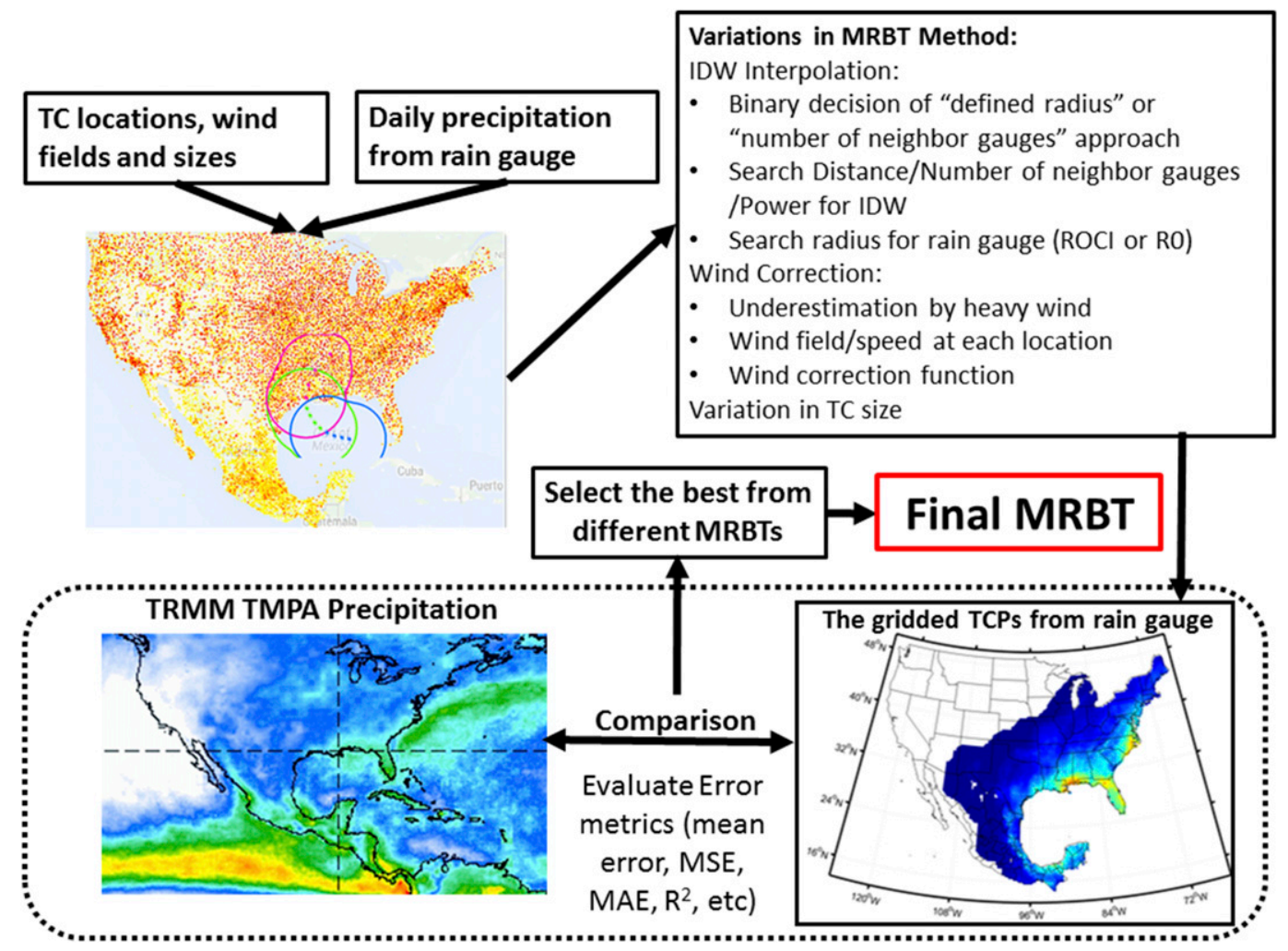

FIG. 1. Flowchart of research design.

the location of each rain gauge four times a day. Then the daily average wind speed was used in the wind correction function by the World Meteorological Organization (Sevruk and Hamon 1984) for wind correction of precipitation obtained by rain gauges:

$$
\begin{aligned}
k= & \exp \left\{\left[-0.001 \times \ln \left(I_{\mathrm{pd}}\right)\right]-\left[-0.0082 \times U_{p} \times \ln \left(I_{\mathrm{pd}}\right)\right]\right. \\
& \left.+\left[\left(0.042 \times U_{p}\right)+0.01\right]\right\},
\end{aligned}
$$

with $I_{\mathrm{pd}}=$ daily rainfall intensity $\left(\mathrm{mm} \mathrm{h}^{-1}\right)$ and $U_{p}=$ wind speed during the precipitation at a height of $10-12 \mathrm{~m}$ above the ground $\left(\mathrm{m} \mathrm{s}^{-1}\right)$.

Our TCP extraction technique, the MRBT, uses TC positions (i.e., location of the center of TC circulation) and the extent of TCP (i.e., how far away from the center of circulation does precipitation associated with the TC occur) to locate which rain gauges to include for daily TCP extraction. In this paper, we evaluate two different methods for determining the spatial extent of TCP rain gauge search. ROCI provides an approximation of the total area that a TC covers (Merrill 1984). We merged the four ROCI observations that are available each day into a large extraction boundary for that day. The ROCI information was obtained from the Tropical Cyclone Extended Best Track Dataset compiled by Colorado State
University (Demuth et al. 2006). This dataset provides ROCI for all Atlantic TCs since 1988. Only 5\% of our TC boundaries between 1998 and 2012 are missing, so we used $360 \mathrm{~km}$ (the median value of the existing sample) to replace those missing values. That will not influence the data integrity for the TCP extraction using the ROCI boundary since most of the heavy TCP is located inside $200 \mathrm{~km}$ from the storm's eye (Lonfat et al. 2004). However, the ROCI information was totally missing for TCs that occurred prior to 1988. This may introduce inconsistencies since our future work will involve the longterm reconstruction of TCP since 1920. Therefore, we also tested another option of TC size estimated by another empirical model. The outer radius of vanishing wind (R0) was introduced by Chavas and Emanuel (2010) based on the observation of TCs from the QuikSCAT satellite. Chavas et al. (2016) constructed an empirical relationship between R0 and the local (or relative) SST anomaly (where the anomaly is calculated relative to the global mean SST). Here we calculate R0 between 1998 and 2012 using the approach based on relative SST. We will compare the TCP extraction results between MRBT trials using R0 and ones using ROCI for our current precipitation dataset between 1998 and 2012. Observations of SST are available from the 1920s, so the R0 boundaries are useful for long-term analyses of TCP. 

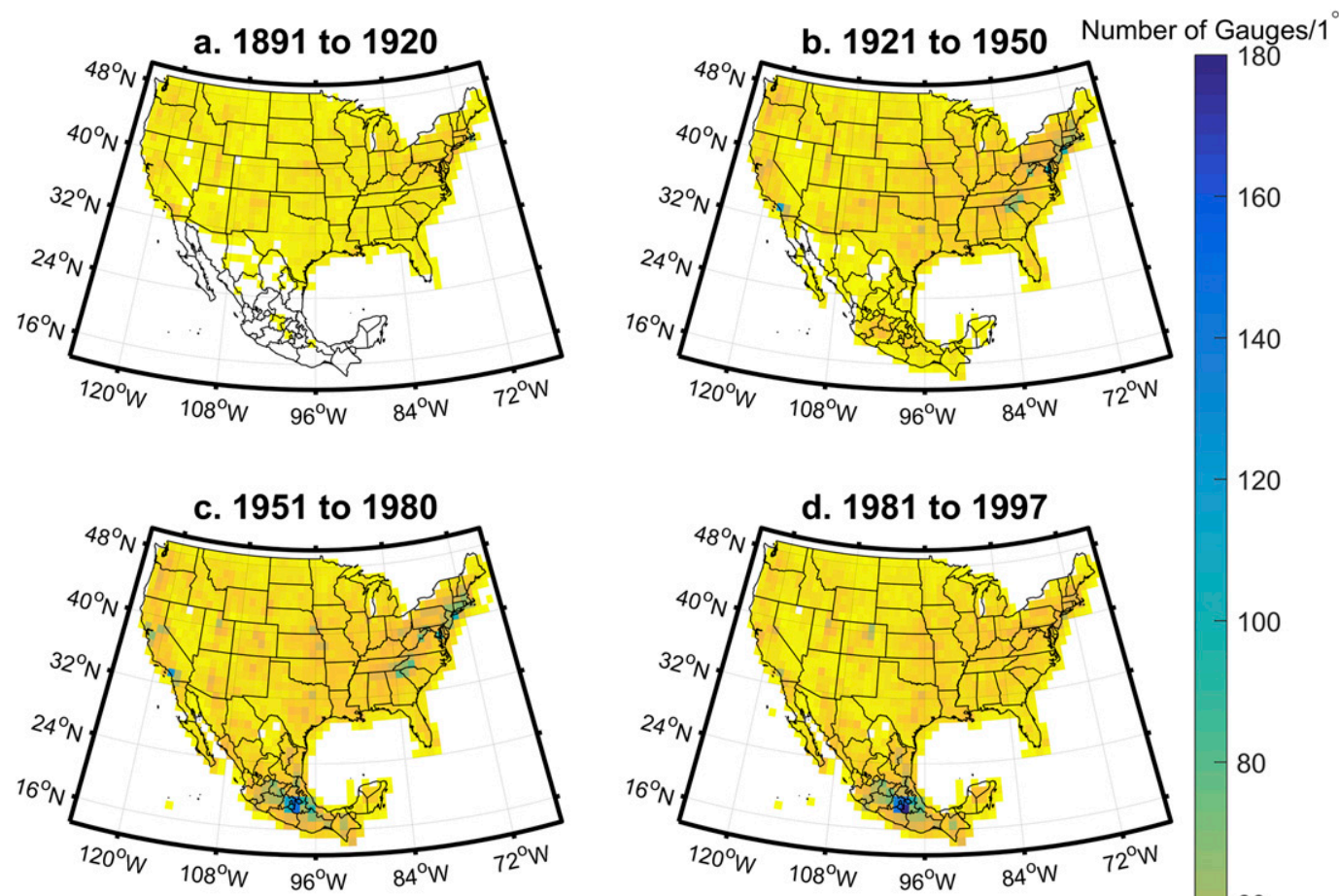

120

100

80
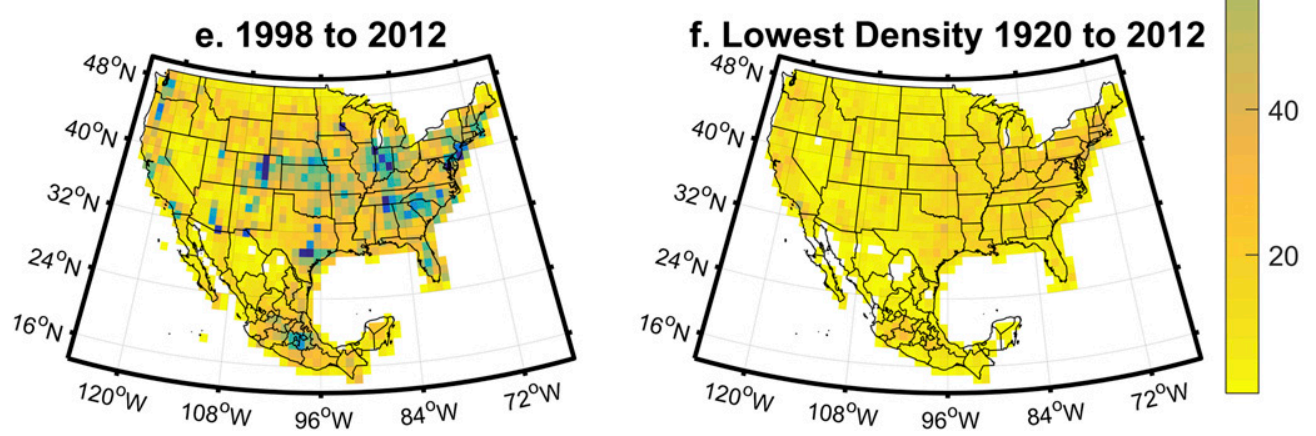

FIG. 2. Number of available gauges in each $1^{\circ}$ latitude/longitude grid cell during five different time periods: (a) 1891-1920, (b) 1921-50, (c) 1951-80, (d) 1981-97, and (e) 1998-2012. (f) A map of the lowest density (fewest gauges during any given year) between 1920 and 2012 is also shown.

Several spatial interpolation approaches can be used to turn the point observation of TCP into a gridded product [inverse distance weighting (IDW), spline, kriging, cokriging]. We use the IDW method to interpolate the irregularly distributed gauge precipitation to a $0.25^{\circ}$ spatial grid. Comparing with other methods, the IDW is a simple but very effective interpolation method that provides very good results in precipitation interpolations with large scale and high resolution (Funk et al. 2015), and it does not need additional inputs other than distances between gauge and interpolation points. The rationale of the IDW is that the value of the target gauge is inversely proportional to the weighted average of its neighbors based on their distances (Shepard 1968). There are two parameters for this method: 1) how many gauges are defined as neighbor gauges and 2) the power of the ratio of the distance (typically distance is squared). Neighboring gauges can be defined in two ways. One way is to use a set number of neighbors at each target location (number of neighbors approach); the other is to define a search radius and use it to identify all neighbors (search radius approach). In this study, we have done tests for many combinations of wind correction options and interpolation options and finalized eight combinations (Table 1) that demonstrate relatively low bias against the TRMM product. Our goal is to find an optimal set of parameters that maximizes the agreement between the gauge- and TRMM-based gridded TCP. We also develop separate accuracy assessments for both the full available gauge density and the lowest historical rain gauge density, 
TABLE 1. List of IDW parameters used in each of the eight methods that were evaluated (MRBT1 is italicized for the previous version of interpolation and MRBT7 is bolded for the final chosen interpolation, which also apply in Tables 2-5).

\begin{tabular}{lclc}
\hline \hline Name & IDW power & IDW method & Distance or No. of gauges \\
\hline MRBT1 & -1.2 & Search distance & $60 \mathrm{~km}$ \\
MRBT2 & -1.2 & Nearest gauge & 5 gauges \\
MRBT3 & -1.4 & Search distance & $60 \mathrm{~km}$ \\
MRBT4 & -1.4 & Nearest gauge & 5 gauges \\
MRBT5 & -1.5 & Search distance & $100 \mathrm{~km}$ \\
MRBT6 & -1.5 & Nearest gauge & 8 gauges \\
MRBT7 & $-\mathbf{1 . 6}$ & Search distance & $\mathbf{8 0 ~ k m}$ \\
MRBT8 & -1.6 & Nearest gauge & 6 gauges \\
\hline
\end{tabular}

as well as TCP variations when we use ROCI and R0 as gauge extraction boundaries.

\section{Results}

\section{a. Finding the optimal IDW combination for the $M R B T$}

We tested eight IDW combinations with four scenarios: 1) complete rain gauge density with wind correction, 2) complete rain gauge density without wind correction, 3) lowest historical rain gauge density without wind correction, and 4) lowest historical rain gauge density with wind correction. We calculated the mean squared error (MSE), mean absolute error (MAE), mean error, and mean relative error (calculated as mean error divided by TRMM) using the TRMM-based TCP as the reference. The statistics for these four scenarios are provided in Tables 2-5.

The different IDW methods have a substantial different impact on the error statistics. All eight MRBTs have negative mean errors and relative errors (columns 4 and 5) in all four scenarios, showing that the total mean value of MRBT-estimated TCP is larger than the

TABLE 2. Mean error statistics for TCP errors calculated between the TRMM and MRBTs using the 1998-2012 precipitation data based on the full rain gauge density without wind correction of rain gauge observation.

\begin{tabular}{lcccc}
\hline \hline & MSE $\left(\mathrm{mm}^{2}\right)$ & MAE $(\mathrm{mm})$ & Error $(\mathrm{mm})$ & $\begin{array}{c}\text { Relative error } \\
\text { (no unit) }\end{array}$ \\
\hline MRBT1 & 534.28 & 14.84 & -1.39 & -6.29 \\
MRBT2 & 603.25 & 13.43 & -0.35 & -2.83 \\
MRBT3 & 507.31 & 14.17 & -1.27 & -5.72 \\
MRBT4 & 614.28 & 13.52 & -0.35 & -2.82 \\
MRBT5 & 498.85 & 13.89 & -1.19 & -5.44 \\
MRBT6 & 580.15 & 13.22 & -0.37 & -2.88 \\
MRBT7 & $\mathbf{4 9 3 . 9 6}$ & $\mathbf{1 3 . 6 5}$ & $\mathbf{- 1 . 1 2}$ & $\mathbf{- 5 . 1 6}$ \\
MRBT8 & 609.71 & 13.47 & -0.36 & -2.85 \\
\hline
\end{tabular}

TABLE 3. Mean error statistics for TCP errors calculated between the TRMM and MRBTs using the 1998-2012 precipitation data based on the full rain gauge density with wind correction of rain gauge observation.

\begin{tabular}{lcccc}
\hline \hline & MSE $\left(\mathrm{mm}^{2}\right)$ & MAE $(\mathrm{mm})$ & Error $(\mathrm{mm})$ & $\begin{array}{c}\text { Relative error } \\
\text { (no unit) }\end{array}$ \\
\hline MRBT1 & 538.63 & 15.62 & -4.02 & -7.22 \\
MRBT2 & 700.54 & 14.43 & -2.86 & -3.33 \\
MRBT3 & 515.93 & 14.94 & -3.88 & -6.58 \\
MRBT4 & 714.58 & 14.53 & -2.86 & -3.32 \\
MRBT5 & 511.00 & 14.66 & -3.79 & -6.26 \\
MRBT6 & 671.27 & 14.20 & -2.88 & -3.37 \\
MRBT7 & $\mathbf{5 1 0 . 5 2}$ & $\mathbf{1 4 . 4 3}$ & $\mathbf{- 3 . 7 1}$ & $-\mathbf{5 . 9 5}$ \\
MRBT8 & 708.88 & 14.48 & -2.87 & -3.34 \\
\hline
\end{tabular}

TRMM estimation since errors are calculated as TRMM minus MRBT. MRBT1 is an empirically chosen parameter set based on our previous study of TCP in Texas (Zhu and Quiring 2013). We evaluated four types of error statistics for the eight MRBTs. MRBT1 has larger errors than the other seven approaches. Generally, approaches using a defined number of neighbor gauges (MRBT approaches 2, 4, 6, 8) have slightly smaller MAE, mean error, and relative error than the approaches using a search distance. We decided to use MRBT7 for TCP extraction because it has the lowest MSE for the complete rain gauge scenario (Tables 1 and 2), and it also has relatively low MSE in the low rain gauge scenario (Tables 4 and 5). It has the most stable performance and lowest error statistics across different trials.

Figure 3 shows the histogram distribution lines of daily TCP errors calculated as MRBT minus TRMM (negative error means underestimate), for all four scenarios and all eight methods that were tested. The bolded distribution curves show two very important combinations: 1) MRBT1 with no wind correction (black solid line) and 2) the wind-corrected MRBT7 (red solid line) that

TABLE 4. Mean error statistics for TCP errors calculated between the TRMM and MRBTs using the 1998-2012 precipitation data from gauges sampled by the lowest rain gauge density from 1920 to 2012 without wind correction of rain gauge observation.

\begin{tabular}{lrccc}
\hline \hline & MSE $\left(\mathrm{mm}^{2}\right)$ & MAE $(\mathrm{mm})$ & Error $(\mathrm{mm})$ & $\begin{array}{c}\text { Relative error } \\
\text { (no unit) }\end{array}$ \\
\hline MRBT1 & 736.68 & 17.82 & -3.38 & -9.17 \\
MRBT2 & 1008.38 & 17.86 & -2.90 & -7.55 \\
MRBT3 & 750.20 & 17.66 & -3.35 & -8.91 \\
MRBT4 & 1019.21 & 17.91 & -2.89 & -7.52 \\
MRBT5 & 760.53 & 17.59 & -3.33 & -8.77 \\
MRBT6 & 979.23 & 17.76 & -2.92 & -7.56 \\
MRBT7 & $\mathbf{7 7 2 . 9 8}$ & $\mathbf{1 7 . 5 5}$ & $\mathbf{- 3 . 3 0}$ & $-\mathbf{8 . 6 4}$ \\
MRBT8 & 1012.15 & 17.89 & -2.88 & -7.52 \\
\hline
\end{tabular}


TABLE 5. Mean error statistics for TCP errors calculated between the TRMM and MRBTs using the 1998-2012 precipitation data from gauges sampled by the lowest rain gauge density from 1920 to 2012 with wind correction of rain gauge observation.

\begin{tabular}{lrccc}
\hline \hline & & & & $\begin{array}{c}\text { Relative error } \\
\text { (no unit) }\end{array}$ \\
\hline MRET1 & 799.99 & 19.09 & -5.76 & -10.51 \\
MRBT2 & 1189.23 & 19.29 & -5.21 & -8.70 \\
MRBT3 & 822.92 & 18.93 & -5.72 & -10.22 \\
MRBT4 & 1203.14 & 19.35 & -5.20 & -8.66 \\
MRBT5 & 839.00 & 18.87 & -5.69 & -10.07 \\
MRBT6 & 1151.13 & 19.18 & -5.23 & -8.72 \\
MRBT7 & $\mathbf{8 5 7 . 7 8}$ & $\mathbf{1 8 . 8 3}$ & $-\mathbf{5 . 6 6}$ & $\mathbf{- 9 . 9 2}$ \\
MRBT8 & 1193.87 & 19.32 & -5.19 & -8.67 \\
\hline
\end{tabular}

optimizes the errors as compared to TRMM. In Figs. 3a and 3b, the MRBT7 curve is below the MRBT1 curve in the region of negative values (rain gauge underestimate), showing that the wind correction systematically reduced undercatch introduced by the strong winds associated with TCs. The magnitude of the errors in Fig. $3 b$ has not changed much from Fig. 3a. This indicates that a longterm TCP reconstruction for North America will be generally reliable, even when derived from a relatively low density network of rain gauges. Both Figs. $3 \mathrm{a}$ and $3 \mathrm{~b}$ have more large negative errors than large positive errors for most MRBTs. This indicates that gauge undercatch can be high during these extreme precipitation events.

\section{b. Comparison of errors in TCP extracted by different MRBTs}

In this section we conduct a sensitivity test of annual and daily errors by using different MRBTs and data from both high and low gauge densities. Figures 4 and 5 are maps of TCP errors (MRBT minus TRMM) averaged annually over $0.25^{\circ}$ grids and scatterplots comparing annual TCPs from MRBT and the TRMM. Figures $4 \mathrm{a}$ and $4 \mathrm{~b}$ show results for MRBT1 (without wind correction) and Figs. $4 \mathrm{c}$ and $4 \mathrm{~d}$ show results for MRBT7 (with correction) when using the most complete rain gauge density with the ROCI as the extraction boundary. The results show that for MRBT1 most of the locations with significant undercatch $\left(<-40 \mathrm{~mm} \mathrm{yr}^{-1}\right)$ are located in coastal areas in North Carolina, the Florida peninsula, eastern Texas, eastern Mexico, and the Yucatan Peninsula. Figure 4b confirms Fig. 4a and demonstrates that the largest undercatch in MRBT1 occurs at locations with high mean annual TCP. MRBT7 is a noticeable improvement over MRBT1 because it reduces TCP undercatch in coastal areas. Figure $4 \mathrm{c}$ has fewer locations with large undercatch than Fig. 4a, and it has much less scatter below the 1:1 line (red) in Fig. 4d, especially for locations with high TCP. However, there are still some locations along the eastern coast of Mexico where TCP is underestimated by this method (Fig. 4c). This indicates that the rain gauge density in Mexico may not be sufficient to accurately capture TCP at $0.25^{\circ}$. There are also some locations where MRBT7 overestimates TCP because of the nonselective nature of the wind correction. They are mostly found in the southern U.S. states, including Texas, Louisiana, Alabama, Mississippi, and Georgia.

MRBT1 and MRBT7 were also compared using data from 1998 to 2012 based on gauges sampled by the $1^{\circ}$ boxes of lowest spatial density (Fig. 2e) (low gauge density hereafter) with the extraction boundary defined as R0 (Fig. 5). MRBT1 demonstrates much larger total undercatch when using the low gauge density as compare to the complete rain gauge density (Fig. 4a). Many coastal locations in Fig. 5a have negative errors $<-50 \mathrm{~mm}$. Scatterplots clearly show that majority of TRMM grids with $>150 \mathrm{~mm}$ annual TCP have less TCP than the MRBT1 estimates. This is likely due, in part, to the reduced number of rain gauges. Another reason is that $\mathrm{R} 0$ typically has a larger mean spatial coverage than ROCI and so most locations have a larger number of TCP days, and therefore the errors tend to compound. MRBT7 (Fig. 5c) has a similar issue with increased undercatch, but it still performs much better than MRBT1 (Fig. 5a). MRBT7 also has a better agreement in the scatterplot with the TRMM, with a slight improvement of 0.01 in $R^{2}(0.96)$ as compared to that of MRBT1 (0.95). The locations with the greatest underestimation of TCP are still mostly located in the eastern part of Mexico and coastal areas of the eastern United States.

At the daily level, we calculated the spatial distribution of daily errors in gauge-estimated TCP as MRBT minus TRMM. The center of the plot represents the center of the TC circulation. We calculated the total amount (Fig. 6) and frequency (Fig. 7) of all the undercatch errors at all $0.25^{\circ}$ grid cells inside a $30 \mathrm{~km} \times 30 \mathrm{~km}$ box centered around the storm center. Figures $6 \mathrm{a}$ and $6 \mathrm{~b}$ compare errors from MRBT1 and MRBT7 when using data from the complete gauge density and ROCI as the extraction boundary. Here the locations with the greatest undercatch are typically near the storm center, especially in the front and right half of the storm. This distribution can be attributed to the rainfall asymmetry discussed by Lonfat et al. (2004), which showed that the precipitation anomaly tends to happen in the front-right quadrant of the storm, especially for those that are more intense (category 3-5). Observations and models also both suggest that there is an enhanced frictional convergence in the boundary layer to the front of the storm motion and that may lead to wind and precipitation 

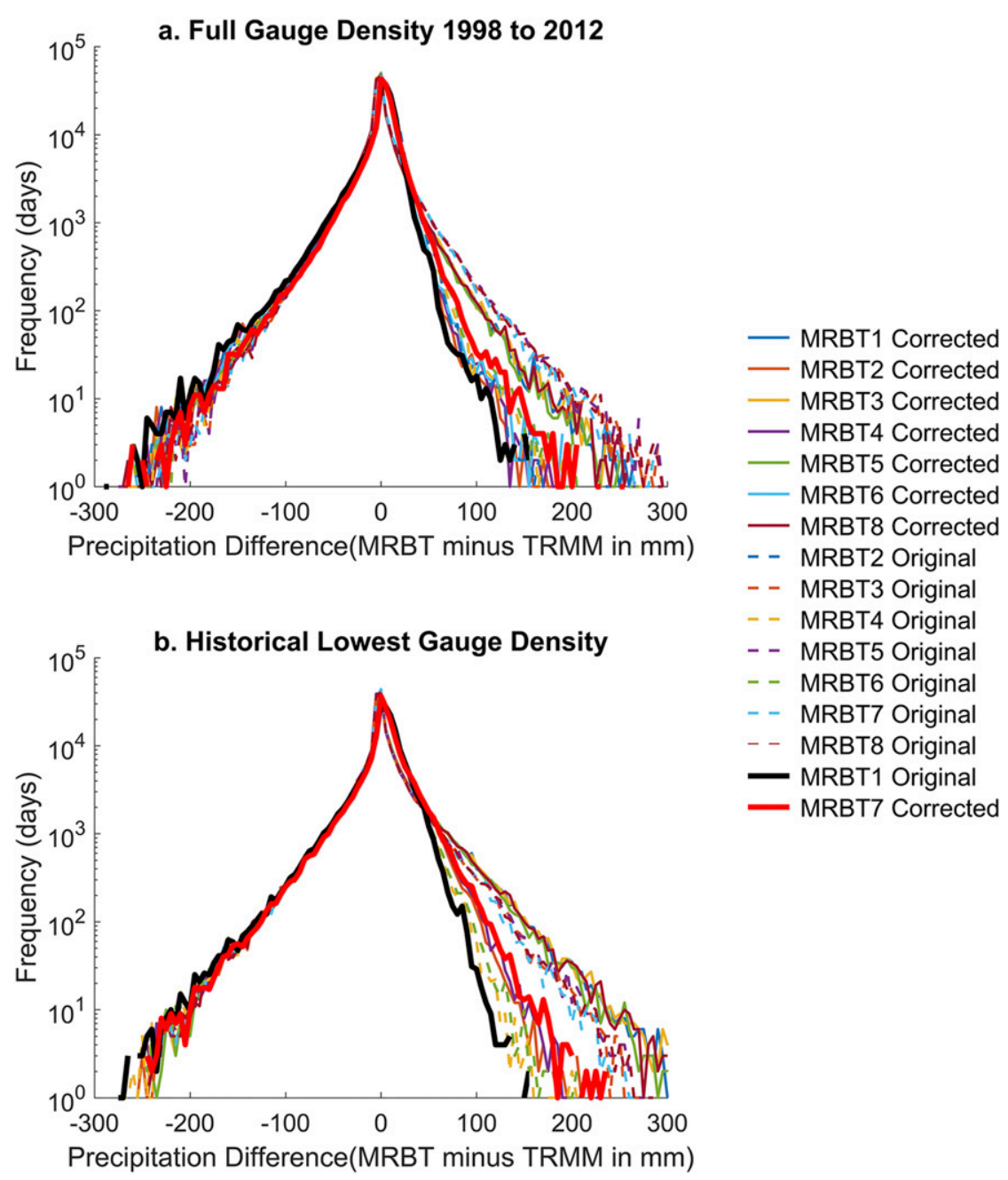

FIG. 3. Comparison of error statistics (MRBT - TRMM) of eight MRBT methods with both original and wind-corrected rain gauge precipitation data by using (a) full gauge density from 1998 to 2012 and (b) gauges sampled by historical lowest gauge density from 1920 to 2012; both use the ROCI as the extraction boundary.

asymmetries (Bender 1997; Chen et al. 2006; Marks 1985; Shapiro 1983; Willoughby et al. 1984). Therefore, those locations with high undercatches are possibly associated with those wind and precipitation asymmetries. In general, MRBT1 has locations with higher values of undercatch. For example, there are clusters of grids with an accumulated error of $\sim 5000 \mathrm{~mm}$ in 15 years. MRBT7 has a similar spatial pattern to MRBT1, but with reduced undercatch at many locations. The locations with the most pronounced reductions tend to be found near the storm center and in the right-front quadrant of the storm.

Figures $6 \mathrm{c}$ and $6 \mathrm{~d}$ show the errors between MRBT1 and MRBT7 when using the lowest rain gauge density and $\mathrm{R} 0$ as the extraction boundary. There is a wider spread of undercatch than in Figs. 6a and 6b. There are more locations with large negative errors $(>2000 \mathrm{~mm})$, and they extend to $>500 \mathrm{~km}$ from the storm center. Meanwhile, undercatch in the central part of the storm has been reduced to $\sim 2500 \mathrm{~mm}$. The front half of the storm has greater errors, and the right-front quadrant has the greatest undercatch. Figure 7 shows the spatial distribution of frequency of undercatch for the same four MRBTs that were discussed in Fig. 6. Their spatial patterns are very similar to Fig. 6. MRBTs using the complete gauge density and ROCI (Figs. 7a,b) have more frequent undercatch than MRBTs using the low gauge density and R0 (Figs. 7c,d). Sparse gauge networks missed some of the TCP events, and they are not included in the calculation of errors with TRMM. R0 has a larger mean value of the extraction boundary, and so the spatial range of undercatch covers a larger area 

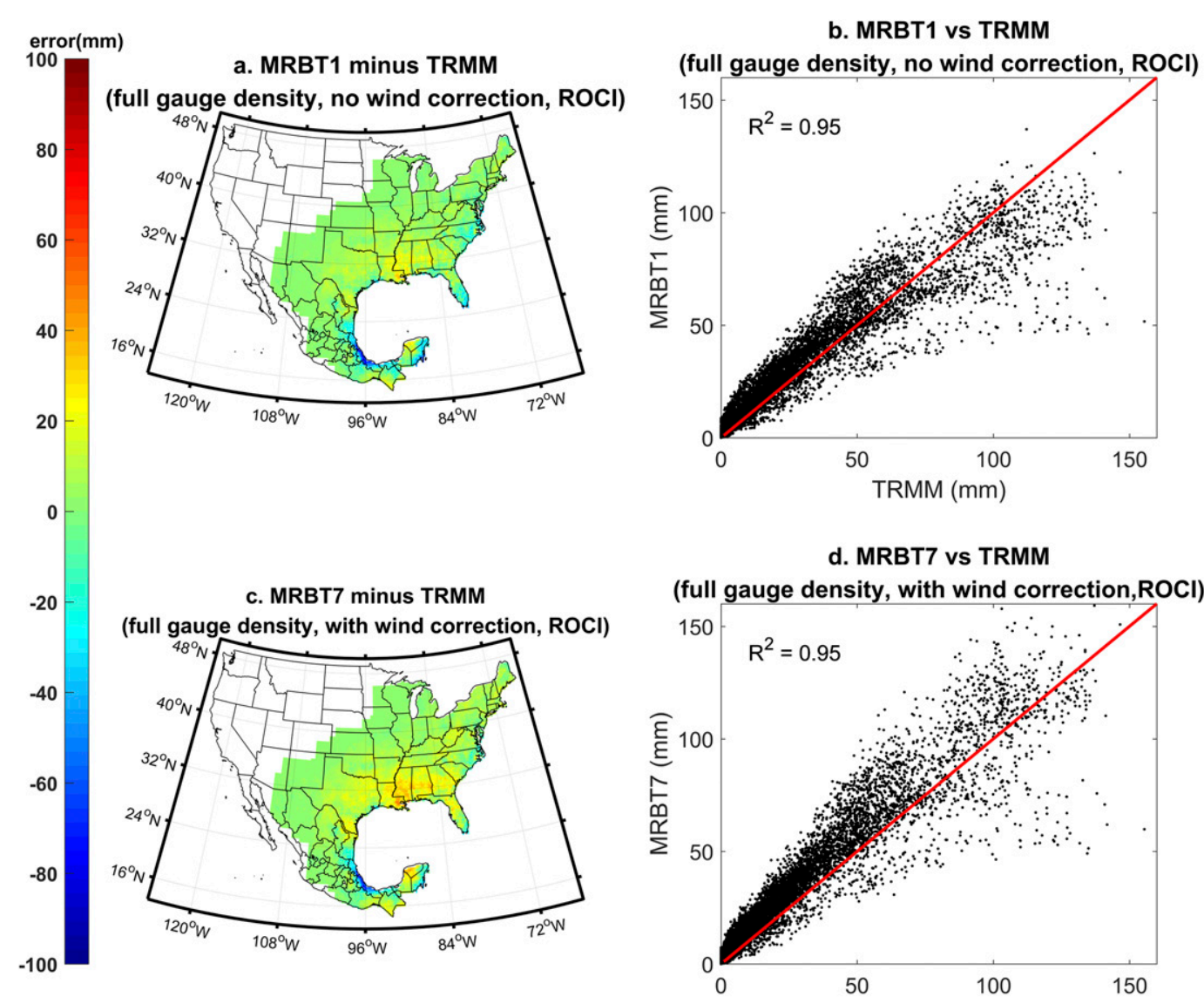

b. MRBT1 vs TRMM

d. MRBT7 vs TRMM

(full gauge density, with wind correction, $\mathrm{ROCl}$ )

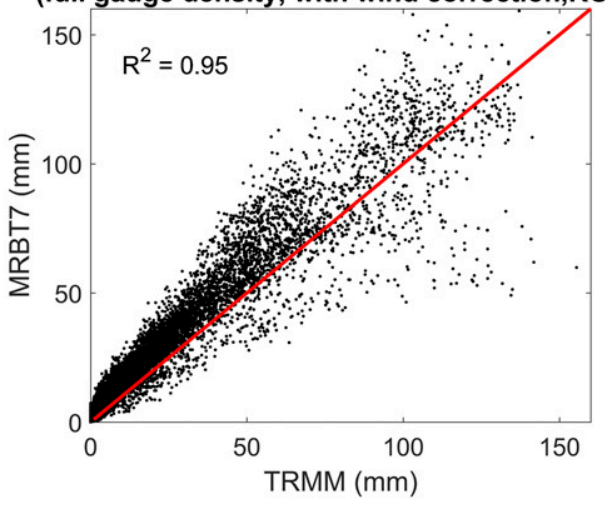

FIG. 4. Spatial pattern of differences (mm) between gauge-based MRBTs and TRMM-based TCP, annually averaged from 1998 to 2012 from the full rain gauge density precipitation data using ROCIs as the extraction boundaries: (a) MRBT1 with no wind correction and (c) MRBT7 with wind correction. (b),(d) Scatterplots show the comparison of annual TCP from MRBT and TRMM. Each dot represents a comparison of the annually aggregated TCP from the gauge-based MRBT7 and TRMM for a single grid cell $(n=9436)$.

than the ROCI approach. The wind correction in MRBT7 has significantly reduced the frequency of undercatch in MRBT1 in both density scenarios.

Intensity is a very important characteristic of TCs. The maximum sustained wind speed can be used to represent intensity. Since we are using a model-simulated wind field for the wind correction of the gauge data, errors in our MRBT TCP estimation may vary with the intensity of the storm. Table 6 shows the number of TCP days between 1998 and 2012 divided by the Saffir-Simpson hurricane intensity definition. We also show results obtained by the two different TCP extraction boundaries of ROCI and R0. The tropical storms with weaker intensity take the majority $(\sim 80 \%)$ of total TCP days. A category 2 storm has the largest sample size of TCP days among all TC categories. We also observed a higher total number of TCP days in the R0 (801) scenario compared to ROCI (549). Our results show that the median value of calculated R0 between 1998 and 2012 is $\sim 800 \mathrm{~km}$, which is more than double the median of ROCIs $(350 \mathrm{~km})$. Using a larger boundary for TCP extraction (R0) results in an increase in TCP days at most locations. While using the smaller ROCI, boundaries may miss some TCP days when the storm center is located on the ocean while a fragment of the storm is generating rainfall on land.

Figure 8 shows how the MRBT undercatch (negative errors calculated as MRBT minus TRMM) and rootmean-square error (RMSE) vary across different storm categories. Each box plot in a color represents a group of error statistics for a MRBT method. In addition, we computed the median value for each group in Fig. 8 in Tables 7 and 8 . We discovered that the mean and median of errors are not proportional to the intensity of the storm. Visually, category 2 and 3 storms have higher errors than other category storms, while tropical storms and category 5 storms have lower errors. The MannWhitney nonparametric $U$ test compares the magnitude of values of two groups (Mann and Whitney 1947). We 

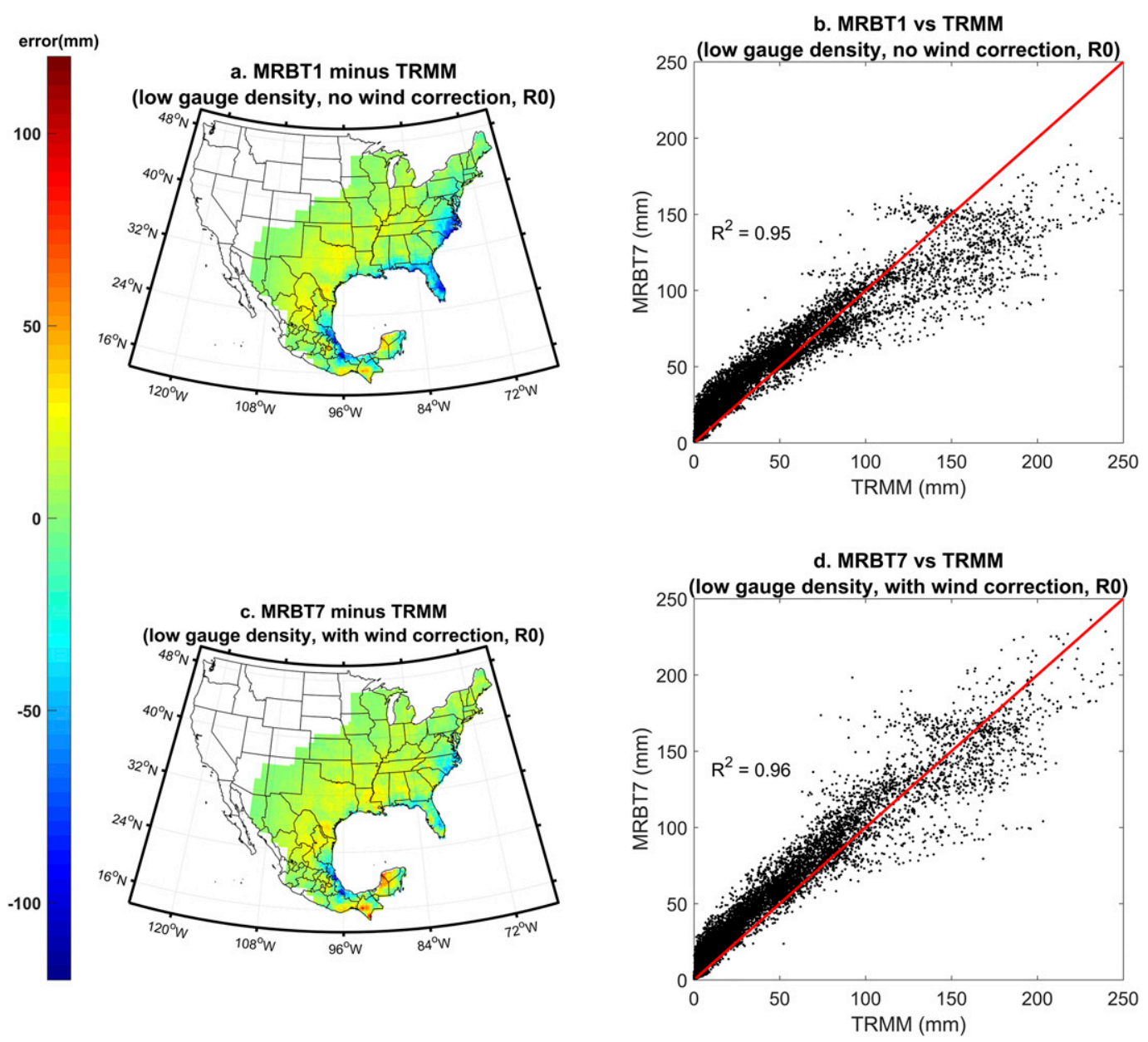

FIG. 5. Spatial pattern of differences $(\mathrm{mm})$ between gauge-based MRBTs and TRMM-based TCP, annually averaged from 1998 to 2012 from the precipitation data spatially sampled by the lowest rain gauge density between 1920 and 2013 using R0 as the extraction boundary: (a) MRBT1 with no wind correction and (c) MRBT7 with wind correction. (b),(d) Scatterplots show the comparison of annual TCP from MRBT and TRMM. Each dot represents a comparison of the annually aggregated TCP from the gauge-based MRBT7 and TRMM for a single grid.

conducted the Mann-Whitney $U$ test for pair groups of errors (both the negative errors and RMSE) from the same MRBT method from different storm categories. Results show that most pairs are not significantly different. Tropical storms have statistically significantly less error than category 2 and category 3 hurricanes at a 95\% significance level. Inside each category of storm, there are differences among groups of errors from different MRBTs, variations in gauge density, and extraction boundaries. We observed smaller errors from the MRBT approaches using the low rain gauge density but larger TCP searching boundaries. That is most likely caused by more grids with a smaller amount of precipitation included by the larger TCP searching boundary and fewer rain gauges available for interpolation. We also used the Mann-Whitney $U$ test to compare groups of errors obtained from different MRBTs within tropical storms and category 2 storms. Tropical storms account for $80 \%$ of all TCP days, and category 2 storms have the highest mean and median error statistics. Results (Fig. 8, Tables 7 and 8, and Tables S1-S4 in the online supplemental material) show that MRBTs using the low gauge density have statistically significantly lower mean RMSEs than MRBTs using the complete gauge density. In addition, MRBT7 has smaller median values of undercatch (Table 7) than MRBT1 for most storm categories. However, it has slightly larger median RMSEs than the MRBT1 in some storm categories (Table 8).

\section{c. Comparison of TCP amount extracted by different MRBTS}

In this section, we evaluate the differences in TCP amount estimated by each MRBT method by comparing 

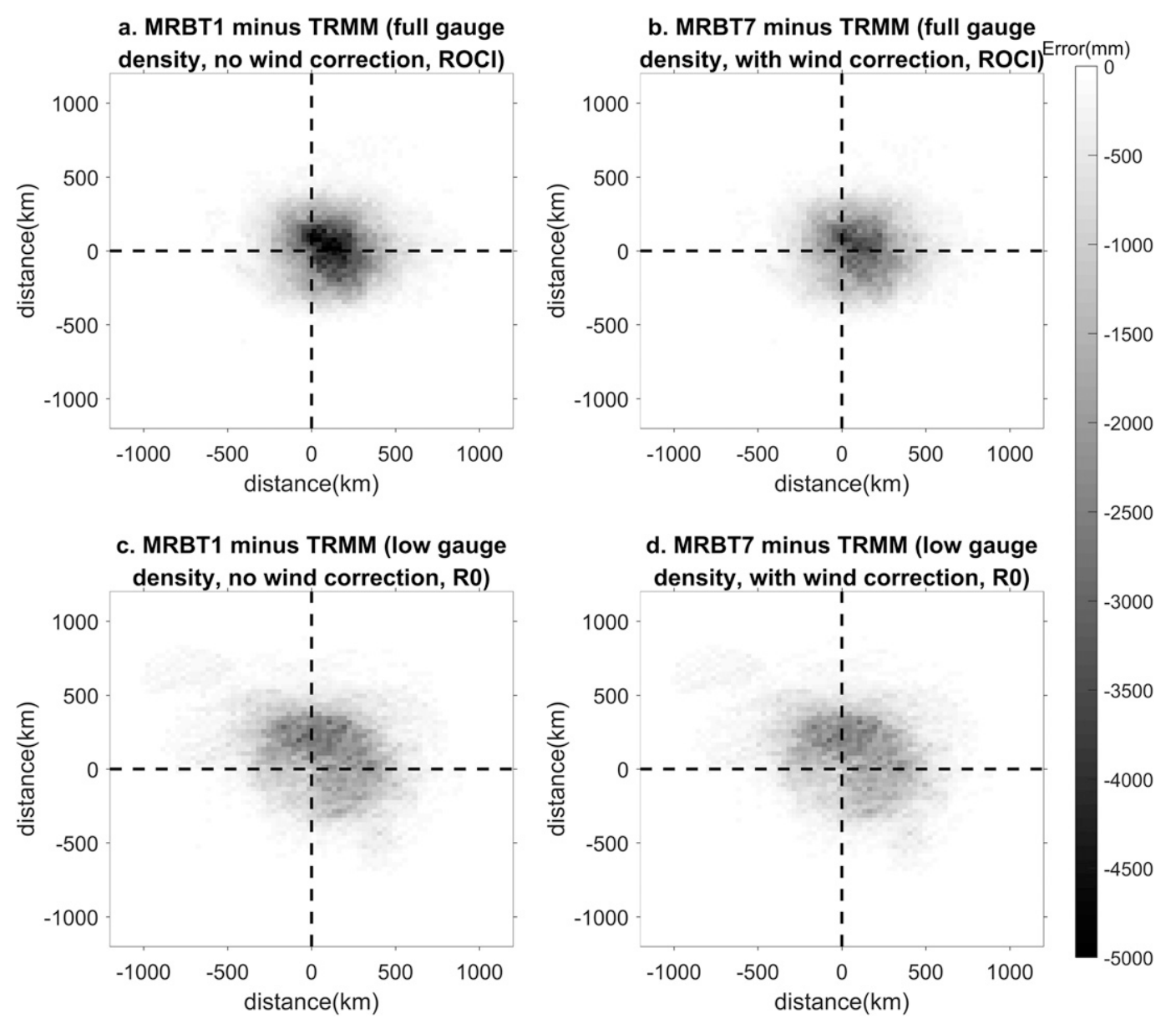

FIG. 6. Spatial distribution of accumulative daily TCP undercatches based on different MRBT techniques when compared with TRMM (MRBT - TRMM). Each graph represents a combination of gauge density (full and lowest), wind corrections (with and without), and outside boundaries used for extraction (ROCI or R0). Daily values were aggregated in $30-\mathrm{km}$ boxes $\left(\sim 0.25^{\circ}\right)$ in a 15 -yr period between 1998 and 2012, organized by the daily TC center for visualization; the chart is oriented in the direction of storm movement.

histograms of their daily TCP values and their annual TCP amounts. There are more samples in Fig. 9b than Fig. 9a because larger R0 has resulted in more total TCP days. Shapes of three curves in both Figs. 9a and 9b are similar and confirm that all sources of TCP are basically reliable. We have run the Kolmogorov-Smirnov test for all pairs of samples in both Figs. 9a and 9b, and they all have the same continuous distribution at the $95 \%$ level. The curves of frequency distribution start diverging at the daily precipitation value slightly larger than $10 \mathrm{~mm}$ in both Figs. 9a and 9b. TRMM (solid) always has the most frequent observations of precipitation larger than $10 \mathrm{~mm}$. The MRBT1 (dotted) curves drop significantly and demonstrate the lowest frequency of greater than $10 \mathrm{~mm}$ precipitation in both plots. The MRBT7 curves (dashed) also have drops when TCP amounts are larger than $10 \mathrm{~mm}$, but the ratio is much slower and approaches the TRMM curves. Figure 9 demonstrates that the
MRBT7 has correct combinations of wind correction and interpolation parameters that significantly improved the undercatch issue (MRBT1) caused by tropical cyclone winds. Those improvements are especially prominent in the extreme events with high TCP observations.

Figure 10 has spatial distributions of annual average TCP from TRMM, MRBT1, and MRBT7 extracted from data of both gauge density with two extraction boundaries. There are less mean and extreme annual TCP for the complete density with ROCI than those from the low density with the R0. Similar to what we observe in Fig. 5, R0 included more cases, so the total annual TCP increases in Figs. 10d-f. MRBT1 maps have many locations where the gauge-estimated annual TCP is less than TRMM, mostly located in the coastal areas, which are associated with wind-induced gauge undercatch. In addition, the differences between MRBT1 and 

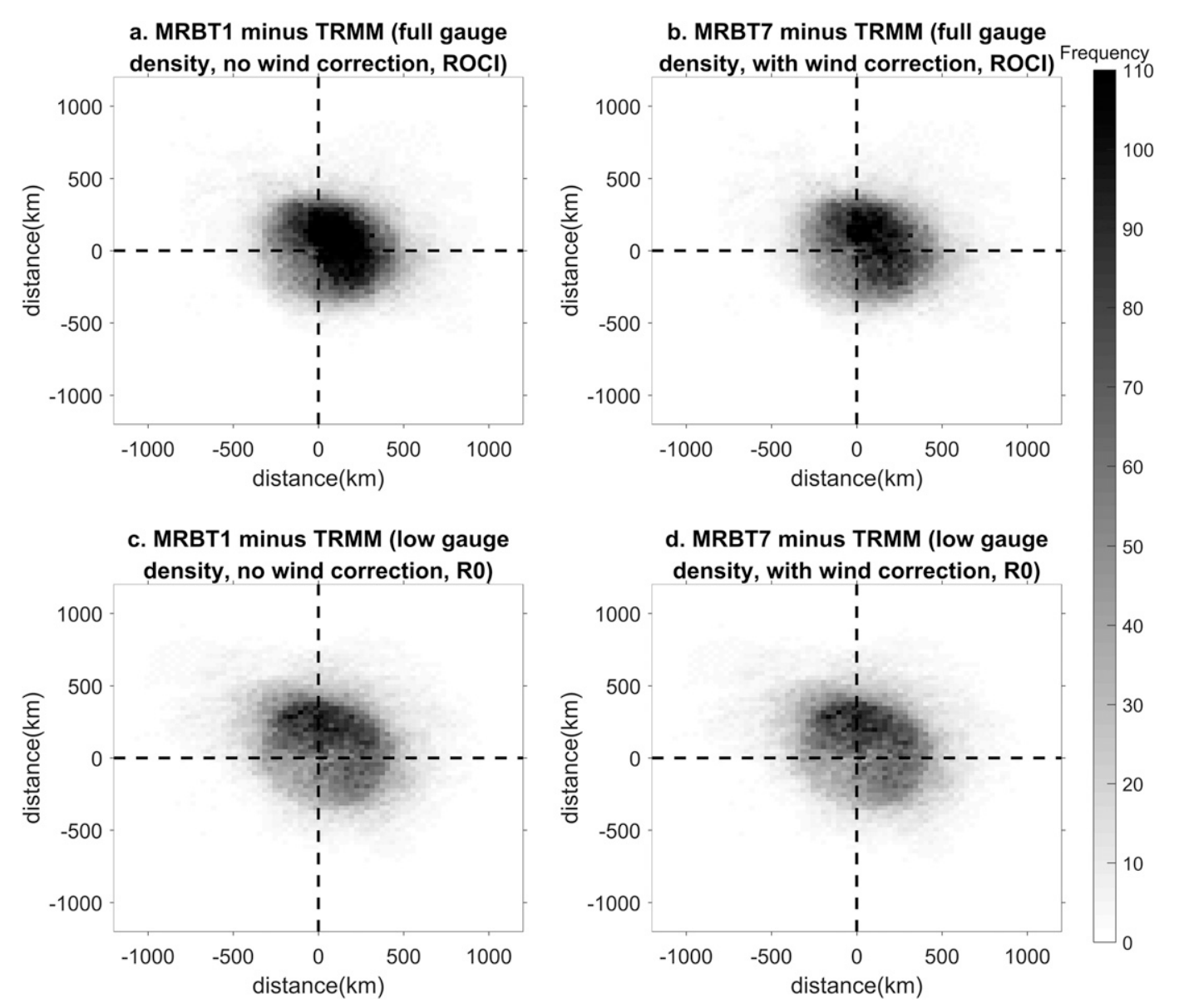

FIG. 7. As in Fig. 6, but for accumulative frequency.

TRMM are much smaller in the complete gauge density with ROCI (Fig. 10b versus Fig. 10a) as compared to the low gauge density with R0 (Fig. 10b versus Fig. 10a). Using MRBT7 results in much better agreement with TRMM, especially in coastal areas. The improvement from using MRBT7 is most pronounced in the low gauge density scenarios. There are still some regions in eastern Mexico along the Gulf of Mexico and the Yucatan Peninsula where MRBT7 does not result in much improvement. We believe that is caused by the very low rain gauge density in this region.

\section{Discussion}

Our study shows that the choice of interpolation parameters of IDW, rain gauge density, and extraction boundary influences the accuracy of the gauge-based TCP. Of particular importance is accounting for gauge undercatch due to wind because previous TCP studies have not explicitly accounted for this factor. We found that our MRBT estimations of TCP are generally in good agreement with TRMM for both the complete and low rain gauge density cases. This confirms findings from previous studies (Chokngamwong and Chiu 2008; Prakash and Gairola 2014; Thiemig et al. 2012) and demonstrates that GHCN-D gauges can be used to develop a reliable record of TCP.

We have designed MRBTs with multiple combined options of parameters to compare with our baseline experiment MRBT1 (which uses empirically chosen

TABLE 6. Saffir-Simpson hurricane classification and TCP days from 1998 to 2012 defined by the ROCI and R0 boundaries $\left(1 \mathrm{kt}=0.51 \mathrm{~m} \mathrm{~s}^{-1}\right)$.

\begin{tabular}{lccc}
\hline \hline \multicolumn{1}{c}{ Category } & $\begin{array}{c}\text { Sustained wind of } \\
\text { storm center }\end{array}$ & \multicolumn{2}{c}{ TCP days TCP days } \\
by ROCI & by R0 \\
\hline Tropical storm & $<64 \mathrm{kt}\left(<119 \mathrm{~km} \mathrm{~h}^{-1}\right)$ & 436 & 621 \\
Category 1 & $64-82 \mathrm{kt}\left(119-153 \mathrm{~km} \mathrm{~h}^{-1}\right)$ & 43 & 85 \\
Category 2 & $83-95 \mathrm{kt}\left(154-177 \mathrm{~km} \mathrm{~h}^{-1}\right)$ & 36 & 43 \\
Category 3 & $96-112 \mathrm{kt}\left(178-208 \mathrm{~km} \mathrm{~h}^{-1}\right)$ & 14 & 24 \\
Category 4 & $113-136 \mathrm{kt}\left(209-251 \mathrm{~km} \mathrm{~h}^{-1}\right)$ & 14 & 23 \\
Category 5 & $>136 \mathrm{kt}\left(>252 \mathrm{~km} \mathrm{~h}^{-1}\right)$ & 3 & 5 \\
\hline
\end{tabular}



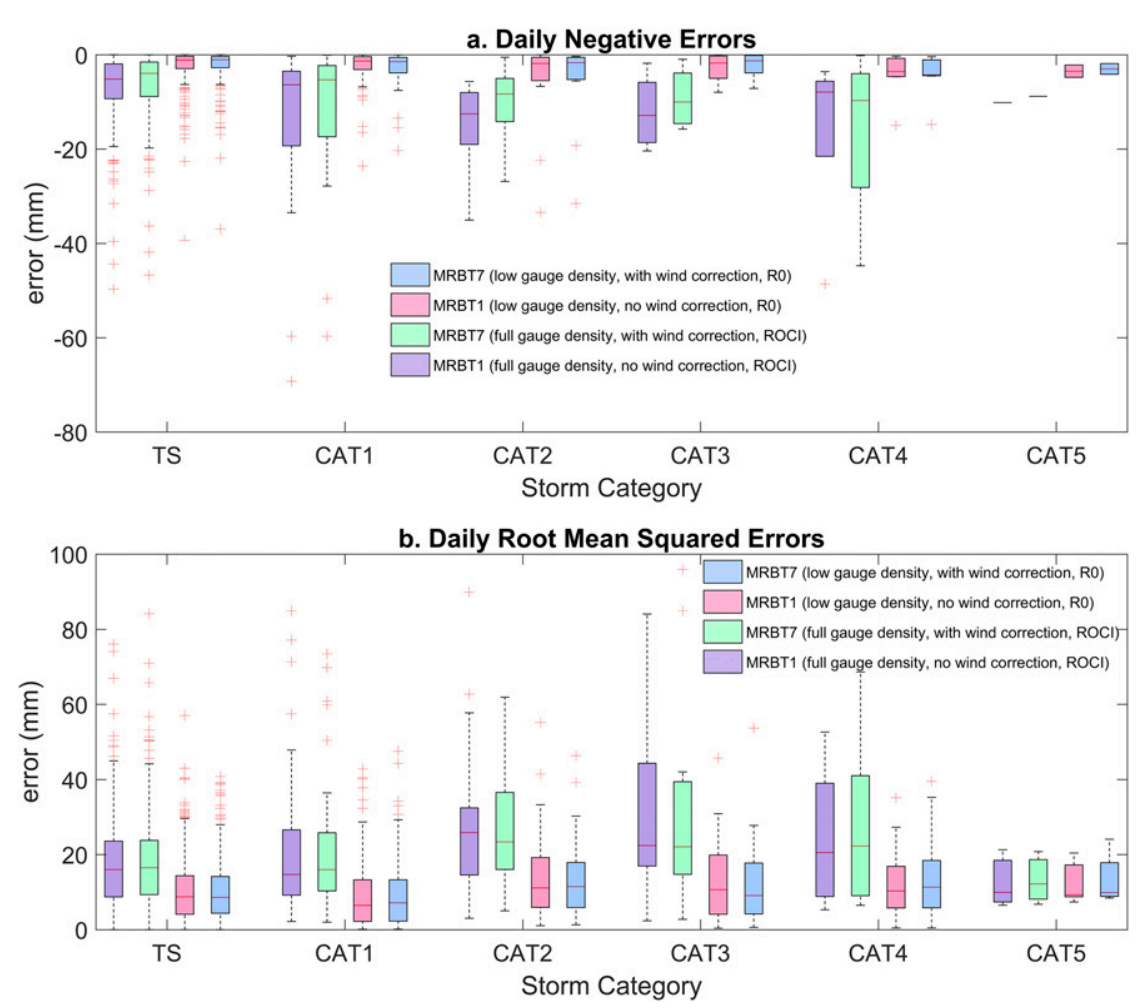

FIG. 8. Box plot of the error statistics [(a) daily negative errors and (b) daily RMSEs] between daily TCP calculated using four variations of MRBT methods and TRMM TCP. Results are summarized using the six Saffir-Simpson intensity categories (defined in Table 6).

IDW parameters with no wind correction; Zhu and Quiring 2013) with the TRMM product as the reference data. We tested many different interpolation approaches and showed that MRBT7 (using a neighbor searching distance of $80 \mathrm{~km}$ with power $=-1.6$ ) is the most accurate method among the ones we have tested. The performance of MRBT7 is also very stable when we have varied the wind correction, gauge density variation, and size of TCP extraction boundary. Specifically, the baseline approach (MRBT1) has significant errors because it does not account for gauge undercatch. The wind correction in MRBT7 significantly reduced gauge undercatch, especially in the larger TCP events.
Spatially, MRBT1 substantially underestimates TCP in coastal locations, especially subtropical and tropical areas $\left(<32^{\circ} \mathrm{N}\right)$. A TC normally maintains structure and intensity well before it makes landfall (Kaplan and DeMaria 1995) from the energy it gains from the warm sea surface temperature (Emanuel 1986). Therefore, higher TC wind speeds near the coast than inland may lead to greater gauge undercatch. Using MRBT7 significantly improved the accuracy of the TCP and reduced undercatch in the larger TCP events and in coastal areas in both the United States and Mexico.

Another reason for the underestimation of TCP in all MRBTs is the spatial and temporal heterogeneity in rain

TABLE 7. Comparison of groups of median values of negative errors (MRBT - TRMM for undercatches) calculated for daily TCPs obtained from different MRBTs; groups are divided by storm categories as in Fig. 8a.

\begin{tabular}{|c|c|c|c|c|}
\hline \multirow[b]{2}{*}{ Groups } & \multicolumn{2}{|c|}{ Complete gauge density } & \multicolumn{2}{|c|}{ Low gauge density } \\
\hline & MRBT1, ROCI & MRBT7, ROCI & MRBT1, R0 & MRBT7, R0 \\
\hline Tropical storm & -5.18 & -3.96 & -1.11 & -1.08 \\
\hline Category 1 & -6.38 & -5.31 & -1.33 & -1.48 \\
\hline Category 2 & -12.55 & -8.34 & -1.86 & -1.69 \\
\hline Category 3 & -12.87 & -10.04 & -1.78 & -1.29 \\
\hline Category 4 & -7.94 & -9.71 & -3.59 & -4.25 \\
\hline Category 5 & -10.15 & -8.83 & -3.49 & -3.02 \\
\hline
\end{tabular}


TABLE 8. Comparison of groups of median values of RMSEs (all positive and negative errors) calculated for daily TCPs obtained from different MRBTs, groups are divided by storm categories.

\begin{tabular}{lccrr}
\hline & \multicolumn{2}{c}{ Complete gauge density } & \multicolumn{2}{c}{ Low gauge density } \\
\cline { 2 - 4 } & MRBT1, ROCI & MRBT7, ROCI & & MRBT1, R0 \\
\hline Tropical storm & 16.00 & 16.48 & 8.77 & 8.60 \\
Category 1 & 14.71 & 15.99 & 6.47 & 7.12 \\
Category 2 & 25.86 & 23.39 & 11.10 & 11.48 \\
Category 3 & 22.39 & 22.08 & 10.66 & 9.09 \\
Category 4 & 20.53 & 22.27 & 10.32 & 11.34 \\
Category 5 & 9.94 & 12.21 & 9.27 & 9.86 \\
\hline
\end{tabular}

gauge density. The undercatch in MRBT1 is larger when we use precipitation data from a low-density rain gauge network. MRBT7 performs much better than MRBT1 in this low gauge density scenario. Despite applying these adjustments, the gauge data still systematically underestimate TCP, compared to TRMM, in some regions. For example, this issue is most pronounced on the eastern Mexico coast and Yucatan Peninsula.

At the daily level, locations with the greatest undercatch are primarily located within $\sim 1000 \mathrm{~km}$ of the storm center. They are mostly near the center and the downshear part of the storm (front half). The area of
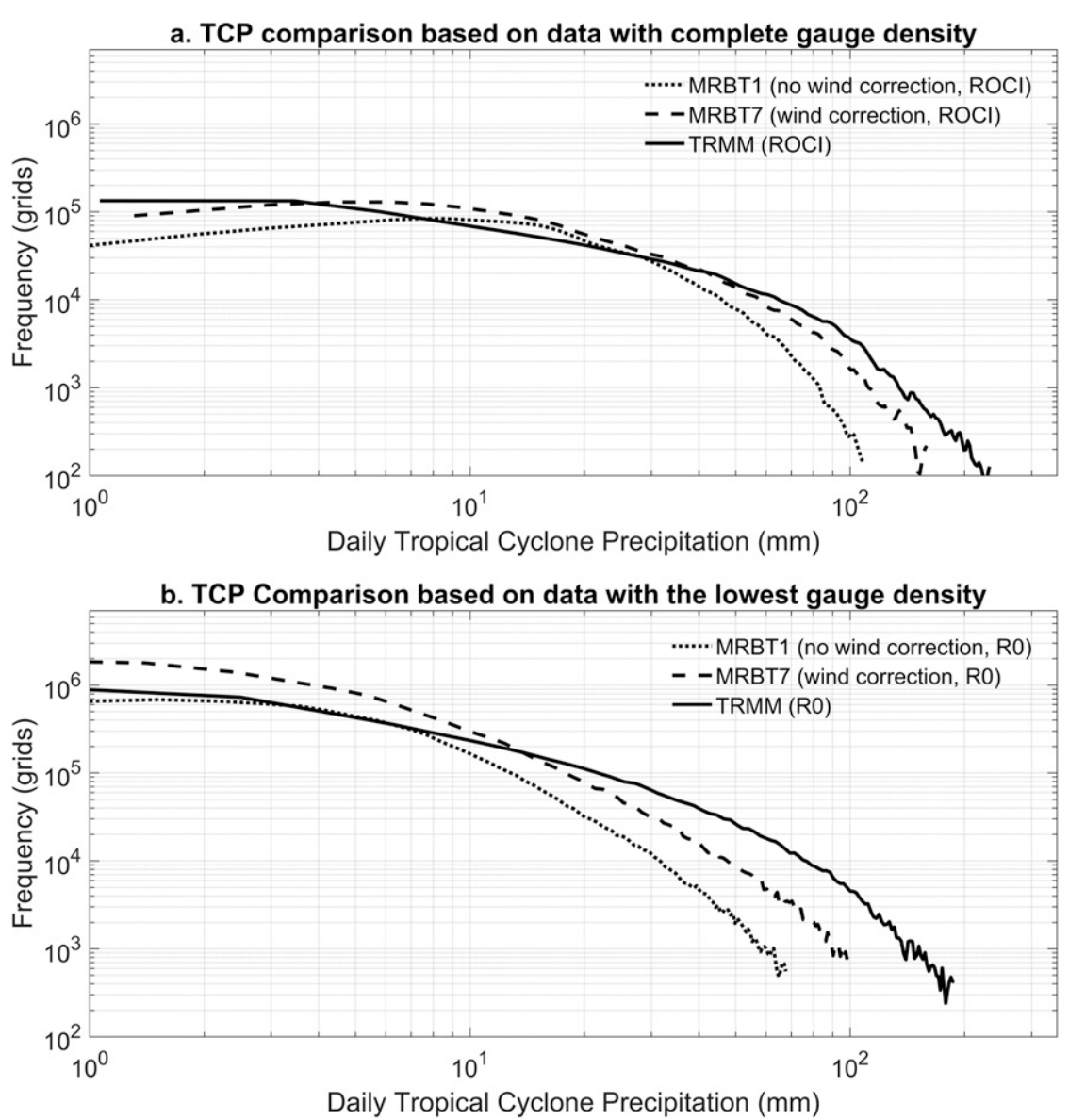

FIG. 9. Distribution of daily TCP amount from MRBTs and TRMM varied by gauge density (full and lowest), wind corrections (with and without), and outside boundaries used for extraction (ROCI or R0). Amount of samples are the same for MRBT1, MRBT7, and TRMM (128257 for Fig. 9a; 401978 for Fig. 9b), and the distribution was fitted using the "histogram" fitting function with the kernel size of 15 in MATLAB. 

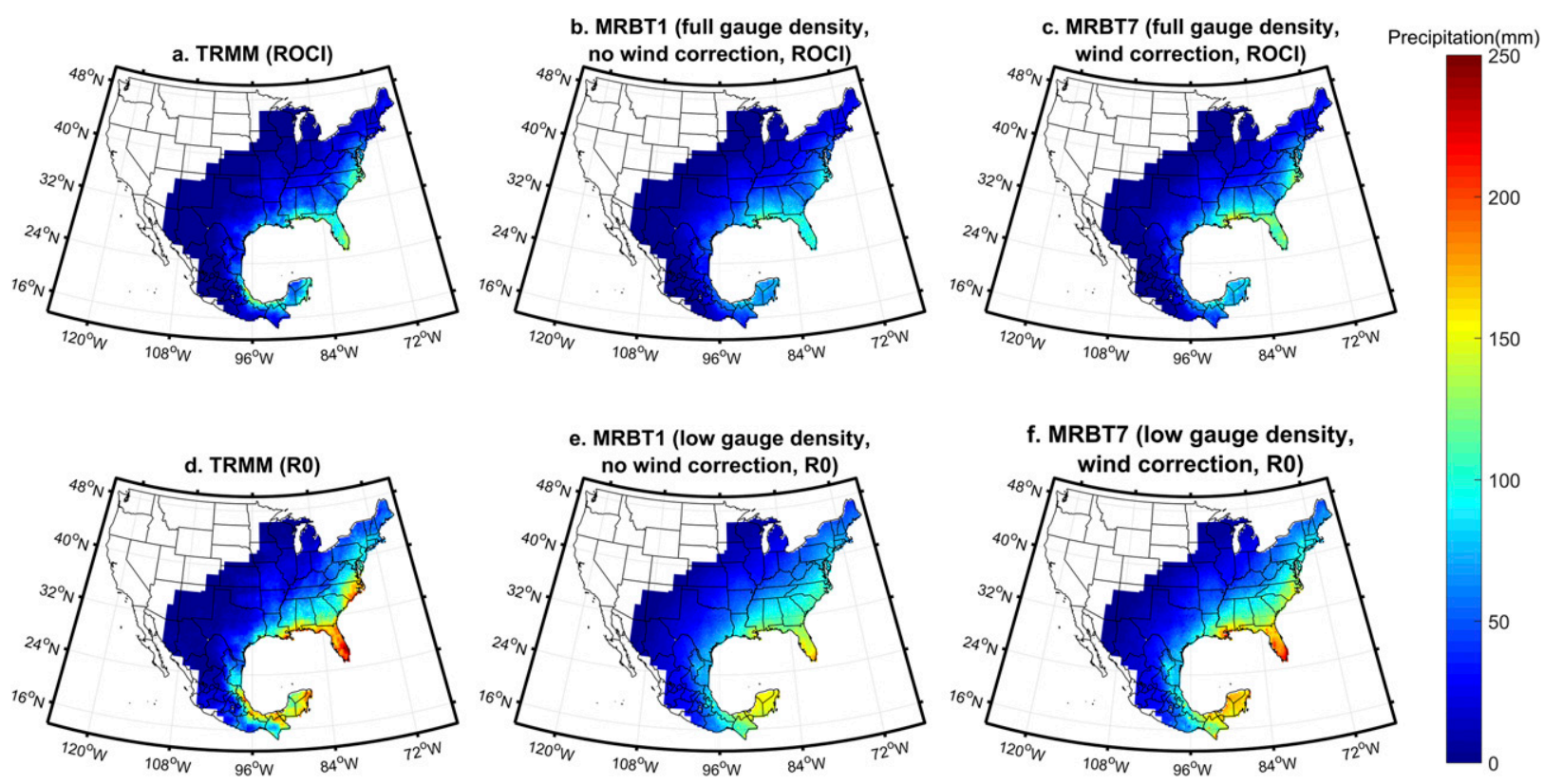

FIG. 10. Spatial distribution of mean annual TCP from 1998 to 2012 for (a) TRMM extracted by ROCI, (b) MRBT1 extracted by ROCI with full rain gauge density and no wind correction, (c) MRBT7 extracted by ROCI with full rain gauge density and wind correction, (d) TRMM extracted by R0, (e) MRBT1 extracted by R0 with low rain gauge density and no wind correction, and (f) MRBT7 extracted by $\mathrm{R} 0$ with low rain gauge density and wind correction.

the storm eye has higher wind speed and precipitation, which leads to a higher possibility of high undercatch by rain gauges. The storm translation and vertical shear are two factors that contribute to the storm rainfall asymmetry because of the spatial differences in the distribution of convection with boundary layer convergence (Chen et al. 2006; Marks 1985). Our results indicate that grids with high daily TCP are the ones with the greatest gauge undercatch. So those spatial asymmetries in TCP are very possibly associated with the high undercatch grids in the front of the storm. Another possible reason for the asymmetrical structure of the undercatch is that rain gauges here only capture precipitation over land, and the front part of the TC is normally the first part that reaches land, with the rest of the storm system still over the ocean. Generally, TCP undercatch is most pronounced in the MRBTs that use a low gauge density and a larger extraction boundary (R0).

Our assessment shows that the accuracy of our approach is not proportional to the intensity of the storm. Category 2 storms have larger errors and greater undercatch than other storm categories. Tropical storms have the lowest errors and least gauge undercatch. Category 5 hurricanes (highest intensity) also have relatively low errors. These results are similar to the observation-based study by Zhu et al. (2013) and the physical modeling study by Knutson and Tuleya (2004). Both show that the strongest storms do not necessarily produce the most precipitation. However, sample size also has an effect, and so category 5 storms may have lower errors because of the limited sample size.

Finally, we also introduced a third precipitation product to evaluate possible uncertainties associated with the TRMM data. The national Stage IV QPE product is a mosaicked multisensor precipitation product (radar + gauges) from 12 River Forecast Centers in the continental United States. It has a spatial resolution of $4 \mathrm{~km}$ and an hourly temporal resolution (Lin and Mitchell 2005). In Fig. 11, we constructed a comparison of TCP estimation from four methods (MRBT7 with wind correction, MRBT1 without wind correction, TRMM, and Stage IV) for the accumulative precipitation in Hurricane Isaac (2012) and Hurricane Irene (2011). The MRBT7, MRBT1, and TRMM are extracted using the ROCI approach, and the Stage IV data are selected accordingly and upscaled to a $0.25^{\circ}$ grid by spatial averaging. It shows that TRMM still underestimates TCP in certain areas for both storms if compared with the Stage IV product. Both Hurricane Isaac and Hurricane Irene are storms with extreme amounts of precipitation. Therefore, it confirms previous studies that the TRMM product can considerably underestimate very heavy precipitation over coastal inland areas (AghaKouchak et al. 2011; Chen et al. 2013a), which is possibly associated with its poor capability to capture the orographic enhancement during TC landfall 

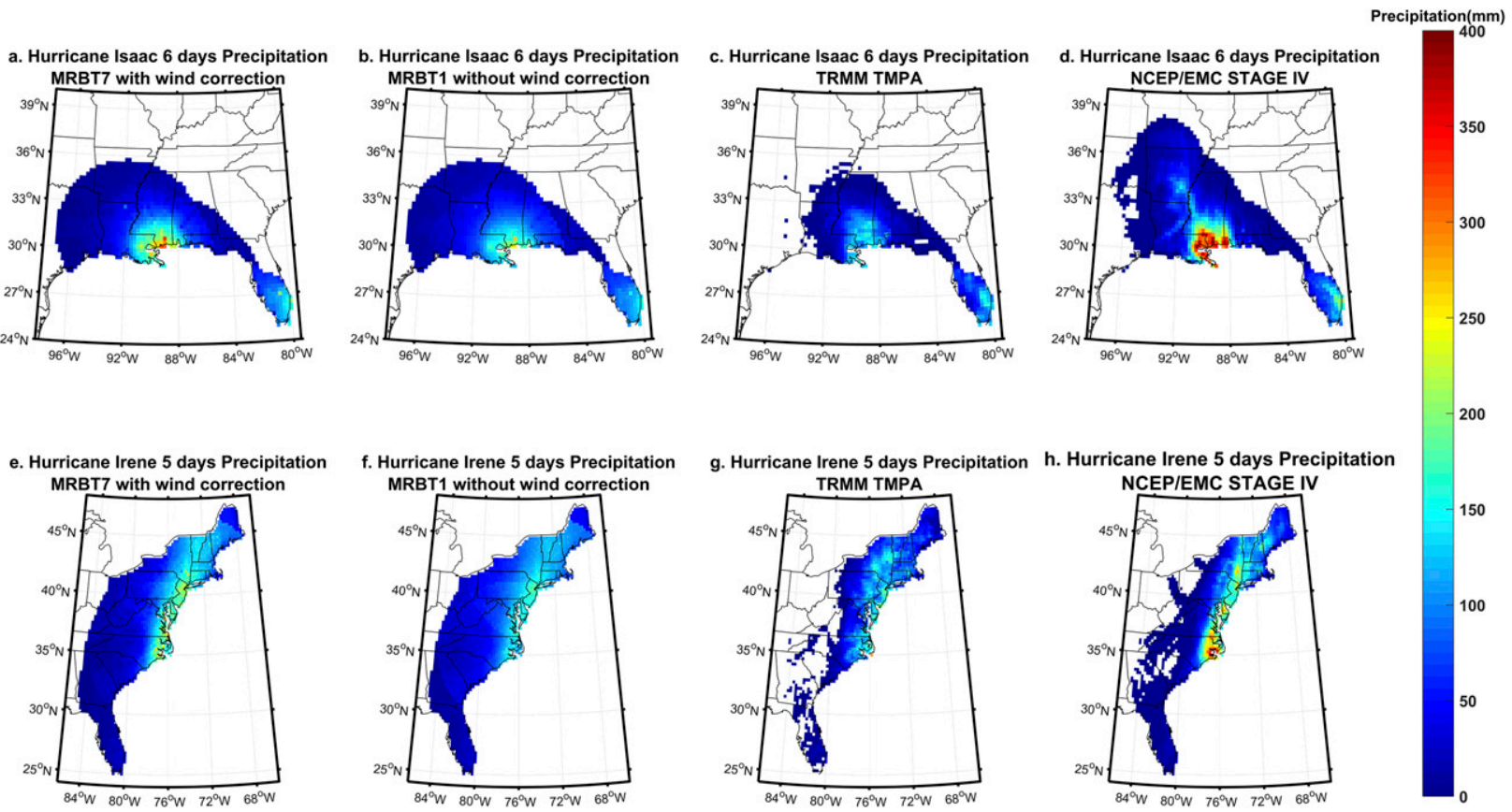

FIG. 11. Spatial distribution of precipitation in two hurricane events: (a)-(d) Hurricane Isaac in 2012 and (e)-(h) Hurricane Irene in 2011. Precipitation is aggregated for each grid for the period of the entire storm. The NCEP/Environmental Modeling Center (EMC) Stage IV map is calculated by averaging all precipitation of $4-\mathrm{km}$ grids within each of the $0.25^{\circ}$ grids.

(Chen et al. 2013b; Smith et al. 2009). The MRBT7 has the best match with Stage IV in terms of spatial distribution and intensity of TCP for both storms. The wind correction used in MRBT7 has systematically increased precipitation amounts as compared with the baseline MRBT1 without wind correction. It indicates that our new extraction methodology has largely improved the accuracy in estimating the precipitation amount in very extreme TCP events. It also suggests that those overestimations of MRBT7 over TRMM in the high value area of Fig. $4 \mathrm{~d}$ could not be purely an artifact of error by the wind correction function we have applied, since TRMM also has underestimations in extreme high precipitation cases, as shown for the two TCs in Fig. 11. Finally, we also need to be cautious when evaluating our methods against Stage IV because the Stage IV product also has many uncertainties in overestimating extreme precipitation and geographical differences because it is a mosaic product by 12 River Forecast Centers (Chen et al. 2015; Eldardiry et al. 2017).

\section{Conclusions}

We developed a new MRBT technique that generates a gridded daily tropical cyclone precipitation product at a resolution of $0.25^{\circ}$ from a rain gauge network. It improves the original MRBT that was developed by Zhu and Quiring (2013) by accounting for the wind-related influence on gauge catch. We verified our method by comparing our TCP estimates to the NASA TRMM product 3B42 (V7). The verification was done iteratively, and many different combinations of wind corrections, spatial interpolation methods, rain gauge densities, and extraction boundaries were tested. This new and improved MRBT method will be applied in the future to study long-term trends and patterns in regional and global daily TCP based on rain gauge observations.

There are significant differences between TCP based on MRBT1 and TCP obtained from TRMM, primarily due to wind-related gauge undercatch. MRBT7 is very effective at reducing these differences, even when tested using a low gauge density. MRBT7 is able to reduce the effect of wind undercatch in coastal areas, and it closely matches the TCP from TRMM.

There are still opportunities to further improve the MRBT7 TCP extraction methodology. The systematic overestimation in the southeastern United States (Louisiana, Mississippi) compared with TRMM might be associated with the wind correction not performing well during extremely high winds. Extreme TC winds exist in this area (Keim et al. 2007) and can proportionally boost the estimation of the wind-corrected precipitation amount with our wind 
correction functions. Another explanation is possibly the underestimation of extreme rain rates in the TRMM product, which has been mentioned many times in past literature (AghaKouchak et al. 2011; Ashouri et al. 2015; Chen et al. 2013a,b; Nicholson et al. 2003) and shown in the Irene and Isaac cases. Our MRBT7 with wind correction has partially improved this. A smaller study region will enable us to compare more precipitation products and have more variations of interpolation methods/parameters in our MRBT to achieve better accuracy. Finally, there are some locations in Mexico where there is a large discrepancy between MRBT7 and TRMM that is difficult to resolve. The most plausible cause is the inconsistent and low rain gauge density on the eastern coast of Mexico and the Yucatan Peninsula. The complex topography in Mexico also adds difficulty in the accurate spatial interpolation of gridded daily TCP. Future work will examine other approaches for improving the accuracy of gauge-based TCP estimation in this region.

Acknowledgments. This work is partially supported by the U.S. National Science Foundation Grant 1331399. The authors also would like to acknowledge the Mexico rain gauge data provided by the Servicio Meteorológico Nacional of the National Water Commission in Mexico. We appreciate the valuable comments and suggestions made by three anonymous reviewers.

\section{REFERENCES}

AghaKouchak, A., A. Behrangi, S. Sorooshian, K. Hsu, and E. Amitai, 2011: Evaluation of satellite-retrieved extreme precipitation rates across the central United States. J. Geophys. Res., 116, D02115, doi:10.1029/2010JD014741.

Ashouri, H., K. Hsu, S. Sorooshian, D. K. Braithwaite, K. R. Knapp, L. D. Cecil, B. R. Nelson, and O. P. Prat, 2015: PERSIANN-CDR: Daily precipitation climate data record from multisatellite observations for hydrological and climate studies. Bull. Amer. Meteor. Soc., 96, 69-83, doi:10.1175/BAMS-D-13-00068.1.

Barlow, M., 2011: Influence of hurricane-related activity on North American extreme precipitation. Geophys. Res. Lett., 38, L04705, doi:10.1029/2010GL046258.

Bender, M. A., 1997: The effect of relative flow on the asymmetric structure in the interior of hurricanes. J. Atmos. Sci., 54, 703-724, doi:10.1175/1520-0469(1997)054<0703:TEORFO>2.0.CO;2.

Benedetti, A., P. Lopez, E. Moreau, P. Bauer, and V. Venugopal, 2005: Verification of TMI-adjusted rainfall analyses of tropical cyclones at ECMWF using TRMM precipitation radar. J. Appl. Meteor., 44, 1677-1690, doi:10.1175/JAM2300.1.

Cerveny, R. S., and L. E. Newman, 2000: Climatological relationships between tropical cyclones and rainfall. Mon. Wea. Rev., 128, 33293336, doi:10.1175/1520-0493(2000)128<3329:CRBTCA > 2.0.CO;2.

Chavas, D. R., and K. A. Emanuel, 2010: A QuikSCAT climatology of tropical cyclone size. Geophys. Res. Lett., 37, L18816, doi:10.1029/2010GL044558.
_ N. Lin, W. Dong, and Y. Lin, 2016: Observed tropical cyclone size revisited. J. Climate, 29, 2923-2939, doi:10.1175/ JCLI-D-15-0731.1.

Chen, S., and Coauthors, 2015: Intercomparison of precipitation estimates from WSR-88D radar and TRMM measurement over continental United States. IEEE Trans. Geosci. Remote Sens., 53, 4444-4456, doi:10.1109/TGRS.2015.2399307.

Chen, S.-Y. S., J. A. Knaff, and F. D. Marks Jr., 2006: Effects of vertical wind shear and storm motion on tropical cyclone rainfall asymmetries deduced from TRMM. Mon. Wea. Rev., 134, 3190-3208, doi:10.1175/MWR3245.1.

Chen, Y., E. E. Ebert, K. J. E. Walsh, and N. E. Davidson, 2013a: Evaluation of TMPA 3B42 daily precipitation estimates of tropical cyclone rainfall over Australia. J. Geophys. Res. Atmos., 118, 11 966-11 978, doi:10.1002/2013JD020319.

,,--- , and,$- 2013 \mathrm{~b}$ : Evaluation of TRMM 3B42 precipitation estimates of tropical cyclone rainfall using PACRAIN data. J. Geophys. Res. Atmos., 118, 2184-2196, doi:10.1002/jgrd.50250.

Chokngamwong, R., and L. S. Chiu, 2008: Thailand daily rainfall and comparison with TRMM products. J. Hydrometeor., 9 , 256-266, doi:10.1175/2007JHM876.1.

Demuth, J. L., M. DeMaria, and J. A. Knaff, 2006: Improvement of Advanced Microwave Sounding Unit tropical cyclone intensity and size estimation algorithms. J. Appl. Meteor. Climatol., 45, 1573-1581, doi:10.1175/JAM2429.1.

Eldardiry, H., E. Habib, Y. Zhang, and J. Graschel, 2017: Artifacts in Stage IV NWS real-time multisensor precipitation estimates and impacts on identification of maximum series. J. Hydrol. Eng., 22, E4015003, doi:10.1061/(ASCE)HE.1943-5584.0001291.

Emanuel, K. A., 1986: An air-sea interaction theory for tropical cyclones. Part I: Steady-state maintenance. J. Atmos. Sci., 43, 585-605, doi:10.1175/1520-0469(1986)043<0585:AASITF>2.0.CO;2.

—, 2013: Downscaling CMIP5 climate models shows increased tropical cyclone activity over the 21st century. Proc. Natl. Acad. Sci. USA, 110, 12 219-12 224, doi:10.1073/pnas.1301293110.

Funk, C., and Coauthors, 2015: The climate hazards infrared precipitation with stations-A new environmental record for monitoring extremes. Sci. Data, 2, 150066, doi:10.1038/ sdata.2015.66.

Habib, E., W. F. Krajewski, V. Nespor, and A. Kruger, 1999: Numerical simulation studies of rain gage data correction due to wind effect. J. Geophys. Res., 104, 19 723-19 733, doi:10.1029/ 1999JD900228.

Hernández Ayala, J. J., and C. J. Matyas, 2016: Tropical cyclone rainfall over Puerto Rico and its relations to environmental and storm-specific factors. Int. J. Climatol., 36, 2223-2237, doi:10.1002/joc. 4490 .

Hill, K. A., and G. M. Lackmann, 2011: The impact of future climate change on TC intensity and structure: A downscaling approach. J. Climate, 24, 4644-4661, doi:10.1175/ 2011JCLI3761.1.

Holland, G. J., J. I. Belanger, and A. Fritz, 2010: A revised model for radial profiles of hurricane winds. Mon. Wea. Rev., 138, 4393-4401, doi:10.1175/2010MWR3317.1.

Jiang, H. Y., and E. J. Zipser, 2010: Contribution of tropical cyclones to the global precipitation from eight seasons of TRMM data: Regional, seasonal, and interannual variations. J. Climate, 23, 1526-1543, doi:10.1175/2009JCLI3303.1.

_ cyclone rapid intensification as derived from 11 years of TRMM data. J. Climate, 26, 6459-6470, doi:10.1175/ JCLI-D-12-00432.1. 
_ J. B. Halverson, and E. J. Zipser, 2008: Influence of environmental moisture on TRMM-derived tropical cyclone precipitation over land and ocean. Geophys. Res. Lett., 35, L17806, doi:10.1029/2008GL034658.

_- C. T. Liu, and E. J. Zipser, 2011: A TRMM-based tropical cyclone cloud and precipitation feature database. J. Appl. Meteor. Climatol., 50, 1255-1274, doi:10.1175/ 2011JAMC2662.1.

Kaplan, J., and M. DeMaria, 1995: A simple empirical model for predicting the decay of tropical cyclone winds after landfall. J. Appl. Meteor., 34, 2499-2512, doi:10.1175/ 1520-0450(1995)034<2499:ASEMFP>2.0.CO;2.

Keim, B. D., R. A. Muller, and G. W. Stone, 2007: Spatiotemporal patterns and return periods of tropical storm and hurricane strikes from Texas to Maine. J. Climate, 20, 3498-3509, doi:10.1175/JCLI4187.1.

Knight, D. B., and R. E. Davis, 2009: Contribution of tropical cyclones to extreme rainfall events in the southeastern United States. J. Geophys. Res., 114, D23102, doi:10.1029/ 2009JD012511.

Knutson, T. R., and R. E. Tuleya, 2004: Impact of $\mathrm{CO}_{2}$-induced warming on simulated hurricane intensity and precipitation: Sensitivity to the choice of climate model and convective parameterization. J. Climate, 17, 3477-3495, doi:10.1175/ 1520-0442(2004)017<3477:IOCWOS > 2.0.CO;2.

— , and Coauthors, 2010: Tropical cyclones and climate change. Nat. Geosci., 3, 157-163, doi:10.1038/ngeo779.

_- and Coauthors, 2013: Dynamical downscaling projections of twenty-first-century Atlantic hurricane activity: CMIP3 and CMIP5 model-based scenarios. J. Climate, 26, 6591-6617, doi:10.1175/JCLI-D-12-00539.1.

Konrad, C. E., and L. B. Perry, 2010: Relationships between tropical cyclones and heavy rainfall in the Carolina region of the USA. Int. J. Climatol., 30, 522-534, doi:10.1002/ joc.1894.

Kunkel, K. E., D. R. Easterling, D. A. R. Kristovich, B. Gleason, L. Stoecker, and R. Smith, 2010: Recent increases in U.S. heavy precipitation associated with tropical cyclones. Geophys. Res. Lett., 37, L24706, doi:10.1029/ 2010 GL045164.

Landsea, C. W., B. A. Harper, K. Hoarau, and J. A. Knaff, 2006: Climate change. Can we detect trends in extreme tropical cyclones? Science, 313, 452-454, doi:10.1126/ science. 1128448.

Lin, Y., and K. E. Mitchell, 2005: The NCEP Stage II/IV hourly precipitation analyses: development and applications. 19th Conf. on Hydrology, San Diego, CA, Amer. Meteor. Soc., 1.2, https://ams.confex.com/ams/Annual2005/techprogram/ paper_83847.htm.

Lonfat, M., F. D. Marks, and S. Y. S. Chen, 2004: Precipitation distribution in tropical cyclones using the Tropical Rainfall Measuring Mission (TRMM) Microwave Imager: A global perspective. Mon. Wea. Rev., 132, 1645-1660, doi:10.1175/ 1520-0493(2004)132<1645:PDITCU>2.0.CO;2

Mann, H. B., and D. R. Whitney, 1947: On a test of whether one of two random variables is stochastically larger than the other. Ann. Math. Stat., 18, 50-60, doi:10.1214/aoms/1177730491.

Mann, M. E., J. D. Woodruff, J. P. Donnelly, and Z. H. Zhang, 2009: Atlantic hurricanes and climate over the past 1,500 years. Nature, 460, 880-883, doi:10.1038/nature08219.

Marks, F. D., 1985: Evolution of the structure of precipitation in Hurricane Allen (1980). Mon. Wea. Rev., 113, 909-930, doi:10.1175/1520-0493(1985)113<0909:EOTSOP>2.0.CO;2.
Matyas, C. J., 2015: Tropical cyclone formation and motion in the Mozambique Channel. Int. J. Climatol., 35, 375-390, doi:10.1002/joc.3985.

Mendelsohn, R., K. Emanuel, S. Chonabayashi, and L. Bakkensen, 2012: The impact of climate change on global tropical cyclone damage. Nat. Climate Change, 2, 205-209, doi:10.1038/ nclimate1357.

Menne, M. J., and Coauthors, 2012: Global Historical Climatology Network - Daily (GHCN-Daily), version 3. Subset used: Version 3.12, NOAA National Climatic Data Center, accessed 20 June 2014, doi:10.7289/V5D21VHZ.

Merrill, R. T., 1984: A comparison of large and small tropical cyclones. Mon. Wea. Rev., 112, 1408-1418, doi:10.1175/ 1520-0493(1984)112<1408:ACOLAS > 2.0.CO;2.

Nicholson, S. E., and Coauthors, 2003: Validation of TRMM and other rainfall estimates with a high-density gauge dataset for West Africa. Part I: Validation of GPCC rainfall product and pre-TRMM satellite and blended products. J. Appl. Meteor., 42, 1337-1354, doi:10.1175/1520-0450(2003)042<1337:VOTAOR > 2.0.CO;2.

Pielke, R. A., Jr., and C. W. Landsea, 1998: Normalized hurricane damages in the United States: 1925-95. Wea. Forecasting, 13, 621631, doi:10.1175/1520-0434(1998)013<0621:NHDITU>2.0.CO;2.

_, J. Gratz, C. W. Landsea, D. Collins, M. A. Saunders, and R. Musulin, 2008: Normalized hurricane damage in the United States: 1900-2005. Nat. Hazards Rev., 9, 29-42, doi:10.1061/(ASCE)1527-6988(2008)9:1(29).

Prakash, S., and R. M. Gairola, 2014: Validation of TRMM-3B42 precipitation product over the tropical Indian Ocean using rain gauge data from the RAMA buoy array. Theor. Appl. Climatol., 115, 451-460, doi:10.1007/s00704-013-0903-3.

Prat, O. P., and B. R. Nelson, 2013: Precipitation contribution of tropical cyclones in the southeastern United States from 1998 to 2009 using TRMM satellite data. J. Climate, 26, 1047-1062, doi:10.1175/JCLI-D-11-00736.1.

Sevruk, B., and W. Hamon, 1984: International comparison of national precipitation gauges with a reference pit gauge. WMO/TD-38, IOM Rep. 17, 20 pp., https://library.wmo.int/ pmb_ged/wmo-td_38.pdf.

Shapiro, L. J., 1983: The asymmetric boundary layer flow under a translating hurricane. J. Atmos. Sci., 40, 1984-1998, doi:10.1175/1520-0469(1983)040<1984:TABLFU>2.0.CO;2.

Shephard, D., 1968: A two-dimensional interpolation function for irregularly-spaced data. Proc. 1968 23rd ACM National Conf., New York, NY, ACM, 517-524, doi:10.1145/800186.810616.

Shepherd, J. M., A. Grundstein, and T. L. Mote, 2007: Quantifying the contribution of tropical cyclones to extreme rainfall along the coastal southeastern United States. Geophys. Res. Lett., 34, L23810, doi:10.1029/2007GL031694.

Smith, R. B., P. Schafer, D. Kirshbaum, and E. Regina, 2009: Orographic enhancement of precipitation inside Hurricane Dean. J. Hydrometeor., 10, 820-831, doi:10.1175/2008JHM1057.1.

Stisen, S., A. L. Hojberg, L. Troldborg, J. C. Refsgaard, B. S. B. Christensen, M. Olsen, and H. J. Henriksen, 2012: On the importance of appropriate precipitation gauge catch correction for hydrological modelling at mid to high latitudes. Hydrol. Earth Syst. Sci., 16, 4157-4176, doi:10.5194/ hess-16-4157-2012.

Thiemig, V., R. Rojas, M. Zambrano-Bigiarini, V. Levizzani, and A. De Roo, 2012: Validation of satellite-based precipitation products over sparsely gauged African river basins. J. Hydrometeor., 13, 1760-1783, doi:10.1175/JHM-D-12-032.1.

Villarini, G., J. A. Smith, M. L. Baeck, T. Marchok, and G. A. Vecchi, 2011: Characterization of rainfall distribution and 
flooding associated with U.S. landfalling tropical cyclones: Analyses of Hurricanes Frances, Ivan, and Jeanne (2004). J. Geophys. Res., 116, D23116, doi:10.1029/2011JD016175.

- D. A. Lavers, E. Scoccimarro, M. Zhao, M. F. Wehner, G. A. Vecchi, T. R. Knutson, and K. A. Reed, 2014: Sensitivity of tropical cyclone rainfall to idealized globalscale forcings. J. Climate, 27, 4622-4641, doi:10.1175/ JCLI-D-13-00780.1.

Walsh, K. J. E., and Coauthors, 2015: Hurricanes and climate: The U.S. CLIVAR working group on hurricanes. Bull. Amer. Meteor. Soc., 96, 997-1017, doi:10.1175/BAMS-D-13-00242.1.

Wang, J., and D. B. Wolff, 2012: Evaluation of TRMM rain estimates using ground measurements over central Florida. J. Appl. Meteor. Climatol., 51, 926-940, doi:10.1175/ JAMC-D-11-080.1.

Willoughby, H. E., F. D. Marks, and R. J. Feinberg, 1984: Stationary and moving convective bands in hurricanes. J. Atmos. Sci., 41, 3189-3211, doi:10.1175/1520-0469(1984)041<3189: SAMCBI $>2.0 . \mathrm{CO} ; 2$.

Yang, D., S. Ishida, B. E. Goodison, and T. Gunther, 1999: Bias correction of daily precipitation measurements for Greenland. J. Geophys. Res., 104, 6171-6181, doi:10.1029/ 1998JD200110.
Zhao, T., and A. Yatagai, 2014: Evaluation of TRMM 3B42 product using a new gauge-based analysis of daily precipitation over China. Int. J. Climatol., 34, 2749-2762, doi:10.1002/joc.3872.

Zhu, L., and S. M. Quiring, 2013: Variations in tropical cyclone precipitation in Texas (1950 to 2009). J. Geophys. Res. Atmos., 118, 3085-3096, doi:10.1029/2012JD018554.

_- O. O. Frauenfeld, and S. M. Quiring, 2013: Seasonal tropical cyclone precipitation in Texas: A statistical modeling approach based on a 60 year climatology. J. Geophys. Res. Atmos., 118, 8842-8856, doi:10.1002/jgrd.50663.

— S. M. Quiring, I. Guneralp, and W. G. Peacock, 2015: Variations in tropical cyclone-related discharge in four watersheds near Houston, Texas. Climate Risk Manage., 7, 1-10, doi:10.1016/j.crm.2015.01.002.

Zick, S. E., and C. J. Matyas, 2016: A shape metric methodology for studying the evolving geometries of synoptic-scale precipitation patterns in tropical cyclones. Ann. Assoc. Amer. Geogr., 106, 1217-1235, doi:10.1080/24694452.2016.1206460.

Zulkafli, Z., W. Buytaert, C. Onof, B. Manz, E. Tarnavsky, W. Lavado, and J.-L. Guyot, 2014: A comparative performance analysis of TRMM 3B42 (TMPA) versions 6 and 7 for hydrological applications over Andean-Amazon river basins. J. Hydrometeor., 15, 581-592, doi:10.1175/JHM-D-13-094.1. 